\title{
Dynamics of shoreface-connected and inactive sand ridges on a shelf, Part 2: The role of sea level rise and associated changes in shelf geometry
}

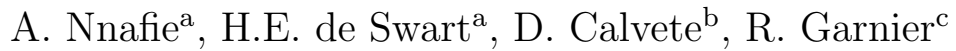 \\ ${ }^{a}$ Institute for Marine and Atmospheric research, Utrecht University, Princetonplein 5, \\ 3584 CC Utrecht, The Netherlands \\ ${ }^{b}$ IDepartament de Física Aplicada, Universitat Politècnica de Catalunya, Campus Nord \\ 08034 Barcelona, Spain \\ ${ }^{c}$ Environmental Hydraulics Institute (IH Cantabria), Universidad de Cantabria, \\ PCTCAN, C/ Isabel Torres 15, 39011 Santander, Spain
}

\begin{abstract}
Many inner continental shelves are characterized by the presence of large 1 rhythmic bedforms, such as shoreface-connected ridges and the more offshore 2 located sand ridges, which have heights of several meters and are spaced sev- 3 eral kilometers apart. This study focuses on explaining the observed orienta- 4 tion difference between shoreface-connected sand ridges and the more offshore 5 located ridges. For this, an existing idealized morphodynamic model is used, $\quad 6$ but modified such that sea level rise simultaneously induces a steepening of 7 the inner shelf and a retreating shoreface. Different settings (rate of sea level 8 rise; landward depth of the inner shelf) are systematically explored. For 9 each setting, the gross characteristics of ridges (growth rate, height, migra- ${ }_{10}$ tion, orientation) during their initial formation and long-term evolution are ${ }_{11}$ quantified. Model results show that a rising sea level and associated shoreface $\quad 12$ retreat and shelf steepening lead to new ridges in the shallow area of the inner 13 shelf, which remain active in time (i.e. ongoing growth and downstream mi- ${ }_{14}$
\end{abstract}

Email addresses: a.nnafie@uu.nl (A. Nnafie), h.e.deswart@uu.nl (H.E. de Swart), daniel.calvete@upc.edu (D. Calvete), garnierr@unican.es (R. Garnier) 
gration in time). Old ridges that were already formed in the antecedent area of the shelf and which in the course of time experience deeper water, become less active with the rising sea level. In the case that migration of the offshore parts of the ridges vanishes, these parts change orientation to become more shore-parallel compared with the active onshore parts of these ridges. In the case of small landward depths of the inner shelf and a decreasing rate of sea level rise, the active onshore parts migrate too fast, thereby causing the drowned offshore parts to detach and to become inactive. The characteristics of modeled shore-oblique shoreface-connected and more parallel offshore located ridges agree with those of observed sand ridges.

Keywords: Holocene, inner shelf, sand ridges, connected, inactive, detached, sea level rise, shoreface retreat, steepening

\section{Introduction}

The rise of mean sea level (MSL) during the Holocene has had a profound impact on the evolution of continental shelves and shores of coastal seas. This is evident from studies (cf. Rampino and Sanders, 1980; Swift and Field, 1981; Stubblefield et al., 1984; Hapke et al., 2010; Schwab et al., 2013) in which coastal evolution was reconstructed from field data. As argued by e.g. Duane et al. (1972) and McBride and Moslow (1991), sea level rise has also had a major impact on the evolution of shoreface-connected sand ridges (hereafter abbreviated as sfcr). These large-scale rhythmic bedforms have heights of up to $12 \mathrm{~m}$, they are spaced apart by $2-10 \mathrm{~km}$, they have a shore-oblique orientation, they evolve on a timescale of centuries and they migrate several meters per year along the coast. Sfcr occur on continental shelves where 
storms generate wave- and wind-induced currents (Duane et al., 1972; Swift ${ }_{37}$ et al., 1978). The continental shelves of the the Mid Atlantic Bight are 38 examples where sfcr occur. Fig. 1 shows sfcr on one of these shelves, viz. the 39 shelf of Long Island off the coast of Fire Island. Field data (Swift et al., 1978; 40 Niedoroda et al., 1984) indicate that sfcr undergo an intermittent process of ${ }_{41}$ development, which is associated with storm wave activity and storm-driven $\quad 42$ currents.

Understanding the dynamics of sfcr is of high interest, because they mod- ${ }_{44}$ ify wind-generated surface waves, thereby causing a complex wave pattern $\quad 45$ that influences coastal sediment transport and related morphological changes $\quad 46$ (Hayes and Nairn, 2004). Any morphodynamic change in these bedforms may ${ }_{47}$ have large impact on beach erosion patterns. Also, recent studies hypothe- 48 size that these ridges may be an important source of sediment to maintain 49 beach stability (Hapke et al., 2010; Schwab et al., 2013). Moreover, because 50 of their proximity to the coast, the ridges are also considered as potential ${ }_{51}$ locations for future offshore wind mill park (Barrie and Conway, 2013). 52

Many studies focused on gaining fundamental insight into the formation $\quad 53$ and long-term evolution of sfcr (Dyer and Huntley, 1999, Hayes and Nairn, 54 2004). McClennen and McMaster (1971) proposed that they are relict fea- ${ }_{55}$ tures from before the Holocene transgression and became submerged during $\quad 56$ a period of sea level rise. Duane et al. (1972) and Swift et al. $(1973,1978) \quad 57$ concluded that the sand ridges evolve from a initial sand source as the latter $\quad 58$ became submerged by the rising sea level and reworked by wave and currents. $\quad 59$ As the coast retreated in response to sea level rise, the ridges experienced 60 larger water depth to become a field of isolated bedforms. McBride and ${ }_{61}$ 
Moslow (1991) postulated that one of the initial sand sources is a segment of an ebb-tidal delta abandoned by inlet migration. However, these models did not explain the shore-oblique orientation and the migration rates of sfcr.

The latter two aspects were explained by Trowbridge (1995), who analysed a simple process-based model and showed that bedforms resembling sfer can form as a result of positive feedbacks between a storm-driven longshore flow and the sandy bed. The underlying mechanism is that a storm-driven flow moving over an upcurrent-rotated ridge (seaward end of the crest is shifted upstream with respect to its landward end) is deflected seaward, as a result of mass conservation. The offshore flow component and the related sand transport decrease with increasing distance to the coast, because of the larger depths, thereby resulting in deposition of sand. Thus, a crucial factor in this model is the occurrence of a transverse bottom slope. The offshore veering of the current over the ridges is supported by field data (Swift et al., 1978; Warner et al. 2014). A drawback of this model is that it was not able to simulate the correct time scales related to growth and migration of these bedforms. Calvete et al. (2001) resolved this problem by including both bedload and suspended load sediment transport and by adding depthdependent stirring of sediment by waves. More recent studies by Calvete and de Swart (2003), Vis-Star et al. (2008) and Nnafie et al. (2011) describe also the long-term evolution of sfcr towards finite heights.

Although these models successfully describe many features of sfcr, they are not able to explain the fact that shoreface-connected sand ridges are in general more obliquely oriented with respect to the present shoreline, while the more offshore located sand ridges (sometimes also called shoreface- 
detached ridges, or 'drowned' ridges (Snedden et al., 2011) or moribund ridges $\quad{ }_{87}$ (Goff and Duncan, 2012)) are more parallel to the shoreline (Fig. 1). Nnafie et al. (2014) used an idealized model to study the impact of sea 89 level rise on the characteristics of sand ridges during their initial and long- 90 term evolution. Different scenarios (rates of sea level rise, geometry of inner 91 shelf) were examined. Their results showed that with increasing sea level the 92 height of sand ridges increases and their migration decreases until they even- ${ }_{93}$ tually drown. Furthermore, their model indicates that if shoreface retreat due 94 to sea level rise is included, new ridges appear in the landward part of the ${ }_{95}$ inner shelf that remain active in time. Old ridges that were already formed 96 in the antecedent part of the inner shelf, which gets located further offshore, $\quad 97$ become less active and drown in the course of time. However, the latter 98 result was based on a rather simple scenario, in which geometrical parame- 99 ters of the inner shelf (slope, width and water depth) have their present-day 100 values, and the rate of sea level rise is $1 \mathrm{~mm} / \mathrm{yr}$. However, geological records 101 (as e.g. presented in Cowell et al., 2003, van Heteren et al., 2011) reveal 102 strong variations in width and steepness of the shelf and shoreface at time ${ }_{103}$ scales of millennia. These variations result from processes like flooding by 104 sea level rise, sediment reworking by waves and tides and sand supply by ${ }_{105}$ rivers. Hutton et al. (2013) demonstrated that sea level rise, in combination ${ }_{106}$ with landward migration of the coastline, leads to shelf steepening due to a 107 seaward increasing water loading on the shelf in the newly created accom- ${ }_{108}$ modation space. Variations in width and slope of the shelf will have a strong ${ }_{109}$ impact on the evolution of sfcr, as Vis-Star et al. (2008) already demon- ${ }_{110}$ strated that steeper bottom slopes result in larger growth rates and smaller ${ }_{111}$ 
migration rates of ridges. Thus, when considering sea level rise, retreat and steepening of the inner shelf, new ridges that form on the landward side of the shelf will grow and migrate differently than ridges that formed on the antecedent part of the shelf.

Of primary interest in the present work is the fundamental understanding of the observed orientation difference between the shoreface-connected ridges and the more offshore located ridges. The key hypothesis in this study is that observed orientation difference between the shoreface-connected ridges and the more offshore located ridges is the consequence of their differential migration rates caused by the rising sea level and the retreating shoreface. To test this hypothesis, runs are conducted with the numerical morphodynamic model used by Nnafie et al. (2014) (called MORFO56), but modified by implementing an equilibrium beach profile that allows for a combined effect of shoreface retreat and shelf steepening due to sea level rise. The LongIsland inner shelf is taken as a study area where both shoreface-connected as well as the more offshore located sand ridges are observed (Fig. 1). With this model, first, the impact of a retreating shoreface and a changing inner shelf geometry (increasing width and slope) on the characteristics (growth rate, height, migration, orientation) of the sand ridges is investigated. Next, the sensitivity of model results to different rates of sea level rise and to different values of the landward water depth of the shelf is examined.

An overview of the model formulation, the setup of the model experiments and tools to analyze model output are given in Section 2. Results are presented in Section 3, followed by a discussion (Section 4) and the conclusions (Section 5). 


\section{Material and Methods}

\subsection{Model formulation}

138

The model governs feedbacks between waves, currents and bottom evo- ${ }_{139}$ lution on the inner and outer shelf. The inner shelf is the transition area ${ }_{140}$ between the relatively steeply sloping nearshore zone and the more gently ${ }_{141}$ sloping outer shelf (Fig. 2). A Cartesian coordinate system is used, with $x$ a ${ }^{142}$ cross-shore, $y$ an alongshore, and $z$ a vertical coordinate. The bed level $z=z_{b} \quad{ }^{143}$ and the sea level $z=z_{s}$ are defined with respect to a reference level $z=0,{ }^{144}$ which corresponds to the mean bottom level (i.e. averaged in the longshore ${ }_{145}$ direction and over a hydrodynamic time scale in the order of days) of the ${ }_{146}$ outer shelf. The reference bed level $\left\langle z_{b}\right\rangle$ is defined as the mean value of $z_{b}$. ${ }_{147}$ Perturbations of the bottom with respect to the reference bed level $z_{b}=\left\langle z_{b}\right\rangle \quad{ }_{148}$ are denoted as $h(x, y, t)$, i.e. $z_{b}=\left\langle z_{b}\right\rangle+h$. The sea level $z=z_{s}=\left\langle z_{s}\right\rangle+\xi, \quad{ }^{149}$ where $\left\langle z_{s}\right\rangle$ indicates the mean sea level (i.e. averaged over a hydrodynamic 150 time scale in the order of days) and $\xi$ is the free surface elevation with respect $\quad 151$ to $z=\left\langle z_{s}\right\rangle$. Furthermore, $H$ is a reference water depth: $H=\left\langle z_{s}\right\rangle-\left\langle z_{b}\right\rangle$, and ${ }_{152}$ $D$ is the total water depth: $D(x, y, t)=z_{s}-z_{b}$. 153

The nearshore zone $\left(x_{c} \leq x \leq x_{i}\right.$, with $x_{c}$ the position of the coastline and ${ }_{154}$ $x_{i}$ the transition between nearshore zone and inner shelf, Fig. 2) is assumed 155 to have the equilibrium bottom profile $\left\langle z_{b}\right\rangle=H_{s}-a\left(x-x_{c}\right)^{2 / 3}$, with $a$ a ${ }_{156}$ sediment scale parameter, which is of the order $0.1 \mathrm{~m}^{\frac{1}{3}}$ for medium to fine ${ }^{157}$ sand (Dean, 1987). The mean bed level $\left\langle z_{b}\right\rangle$ of the entire coastal zone (i.e., ${ }^{158}$ 
nearshore zone, inner shelf and outer shelf) is given by

$$
\left\langle z_{b}\right\rangle= \begin{cases}H_{s}-a\left(x-x_{c}\right)^{2 / 3} & \text { if } x_{c} \leq x \leq x_{i} \\ \beta\left(x_{s}-x\right) & \text { if } x_{i} \leq x \leq x_{s} \\ 0 & \text { if } x>x_{s} .\end{cases}
$$

Here, $\beta$ is a constant slope given by $\beta=\left(H_{s}-H_{i}\right) /\left(x_{s}-x_{i}\right)$, with $H_{i}$ and $H_{s}$ the reference water depths at the transitions between nearshore zone and inner shelf $\left(x_{i}\right)$, and of the outer shelf $\left(x_{s}\right)$, respectively (Fig. 2). In Section 2.2, equations for variables $H_{s}, H_{i}, x_{s}$ and $x_{i}$ are given. The alongshore length of the domain is indicated by $L_{y}$. The cross-shore length of the domain, which increases in time, is equal to $L_{x}-x_{i}(t)$, with $L_{x}$ its length at $t=0$. At location of $x=L_{x}$ it is assumed that bed level $z_{b}$ equals its longshore averaged value $\left\langle z_{b}\right\rangle$.

The wave model is based on linear wave theory (Holthuijsen, 2007). In this study only swell waves are considered. The state variables are the wave frequency $\omega(=2 \pi / T$, with $T$ the wave period $)$, the wavenumber $\kappa$, the angle of wave incidence $\theta$ (see Fig. 2), and the root-mean-square wave height $\mathcal{H}_{\text {rms }}$. From the solutions of the system of equations describing these variables, the root-mean-square amplitude of the near-bed wave orbital velocity $u_{r m s}$ is computed. Explicit formulations are given in the Electronic Supplement (Section A).

Currents (called storm-driven currents) are described by depth- and waveaveraged shallow water equations, which are forced by a combination of a longshore surface wind stress $\tau_{w}$, an alongshore pressure gradient and divergence of the radiation stresses produced by waves. Note that the contribution 
to storm-driven flow due to divergence of the radiation stresses is in general 180 small. Only when wave breaking occurs, as in the case of a small landward 181 part of the inner shelf, this additional forcing becomes more important. The ${ }_{182}$ unknown quantities are the mass transport velocity $\vec{v}$ (components $u, v$ ) and ${ }_{183}$ the free surface elevation $\xi$.

The evolution of the bottom is a result of convergences and divergences in $\quad 185$ the sediment transport, which is assumed to exist only during storm events 186 (Calvete et al., 2001). During these events, sediment transport results from ${ }_{187}$ the combined action of high waves, which stir sand at the bottom, and storm- ${ }_{188}$ driven flow, which subsequently transport this sand as bedload $\left(\vec{q}_{b}\right)$ and sus- ${ }_{189}$ pended load $\left(\vec{q}_{s}\right)$. In addition, a threshold near-bed wave orbital velocity $u_{c} \quad 190$ for erosion is included to account for the fact that sediment transport oc- ${ }_{191}$ curs only if the shear stress exerted on the bed exceeds a critical value. If ${ }_{192}$ the near-bed wave orbital velocity $u_{r m s}$ is smaller than $u_{c}$, sediment trans- ${ }_{193}$ port vanishes. Explicit formulations for the above variables and the used ${ }_{194}$ numerical scheme are given in the Electronic Supplement (Section A). $\quad{ }_{195}$

\subsection{Shelf evolution in response to sea level rise 196}

Studies of the Holocene evolution of the continental shelf of Long-Island ${ }_{197}$ (Rampino and Sanders, 1980; Panageotou and Leatherman, 1986) suggest 198 that the shoreline migrated several kilometers landward as a result of shoreface ${ }_{199}$ retreat induced by sea level rise. A paleo-reconstruction of the shelf evolution 200 on geological time scales is rather complex, viz. shelf and coastal morpholog- ${ }_{201}$ ical changes result from the interaction of a complex array of processes and 202 mechanisms acting over a variety of temporal and spatial scales Niedoroda 203 et al. 1995). In this study, the reconstruction method applied is highly ide- ${ }^{204}$ 
alized. The evolution of the cross-shore bottom profile of the entire coastal zone (including the nearshore zone) is reconstructed by adopting concepts that were applied by Masetti et al. (2008) and Vis-Star et al. (2008). Namely, in their model of the evolution of cross-shore coastal profiles on millennial time scales, they assumed conservation of the total mass of sediment and the conservation of the equilibrium cross-shore beach profile. As steepening of the shelf is an important aspect to be considered (see Section 1), both shoreface retreat as well as shelf steepening are accounted for in the present model (Fig. 3).

As a result of sea level rise, the mean sea level $\left\langle z_{s}\right\rangle$ changes in time according to

$$
\frac{\partial\left\langle z_{s}\right\rangle}{\partial t}=R,
$$

214

with $R$ the rate of sea level rise. The new bottom profile $\left.\left\langle z_{b}\right\rangle\right|_{t+\Delta t}$ of the coastal zone (at $t=t+\Delta t$, with $\Delta t$ a small time increment; red dashed line in Fig. (3) is reconstructed under conditions that the location of the transition inner-outer shelf $x_{s}$ and depth $H_{i}$ at the (retreating) transition nearshore zone-inner shelf $\left(x=x_{i}\right)$ remain unchanged (i.e., $\left.H_{i}\left(x=x_{i}\right)=H_{0}\right)$, while width $L(t)=x_{s}-x_{i}(t)$ and slope $\beta$ of the inner shelf increase in time. Moreover, the bottom profile of the nearshore zone is assumed to maintain its equilibrium shape, while shifting upward and landward in response to a sea level rise. Additionally, its width $w\left(=x_{i}-x_{c}\right)$ is kept constant, which implies that coastal and shoreface retreat equal each other (i.e. $d x_{c} / d t=d x_{i} / d t$ ). By imposing that the eroded sand volume per unit width (A; shaded blue area) in the nearshore zone equals the total sand volume per unit width (B; shaded green area) that is deposited on the inner shelf, it follows (Section B 
of the Electronic Supplement) that the shoreface retreat $d x_{i} / d t$ is given by ${ }^{227}$

$$
\frac{d x_{i}(t)}{d t}=-\frac{\left(x_{s}+2 w\right)}{2 H_{0}} R, \quad x_{i}(0)=0 .
$$

Fig. 4. which shows the rate of shoreface retreat $d x_{i} / d t$ (panel a) and the ${ }_{228}$ bottom slope $\beta=\left(H_{s}-H_{0}\right) /\left(x_{s}-x_{i}\right)$ (panel b) in the $R-t$ space in the case ${ }_{229}$ the parameters $\left(x_{s}, w\right.$ and $\left.H_{0}\right)$ have their present-day values (Section 2.3.1), 230 reveals that $d x_{i} / d t \sim-0.32 \mathrm{~m} / \mathrm{yr}$ in the case that $R=1 \mathrm{~mm} / \mathrm{yr}$ and it ${ }_{231}$ increases to a value of about $-1.58 \mathrm{~m} / \mathrm{yr}$ if $R=5 \mathrm{~mm} / \mathrm{yr}$. The higher is the ${ }^{232}$ rate $R$ the faster is the steepening of the inner shelf (Fig. $4 \mathrm{~b}$ ). 233

\subsection{Methods 234}

2.3.1. Default configuration 235

The model parameters (adopted from Nnafie et al., 2014; an overview of ${ }^{236}$ these parameters is given in Table 1 in the Electronic Supplement) are rep- ${ }^{237}$ resentative for the shelf of Long Island, where both shoreface-connected and ${ }_{238}$ the more offshore located sand ridges are observed (Fig. 1). Reconstructions ${ }_{239}$ of Holocene relative sea level for the US Mid Atlantic coast revealed that the ${ }_{240}$ relative sea level rose at about $2-5 \mathrm{~mm} / \mathrm{yr}$ in the early and mid-Holocene, 241 and it slowed down to approximately $1-2 \mathrm{~mm} / \mathrm{yr}$ in the late Holocene (from 242 $\sim 4000$ years ago to 1900 AD ) (Rampino and Sanders, 1980; Engelhart et al., 243 2011).

In the default experiment, the initial width $L_{0}=L(t=0)$ of the inner ${ }^{245}$ shelf and depth $H_{0}$ at transition $x_{i}$ are equal to their present day values, 246 viz., $L_{0}=5.5 \mathrm{~km}$ and $H_{0}=14 \mathrm{~m}$ (Calvete et al. 2001). Initially, a flat ${ }_{247}$ horizontal bottom of the inner shelf is considered $\left(H_{s}(t=0)=H_{0}\right)$. The ${ }^{248}$ 
system of equations (Section A in the Electronic Supplement and Eqs. for $\left.x_{i}, x_{c},\left\langle z_{s}\right\rangle\right)$ is solved on a domain with lengths $L_{x}-x_{i}$ and $L_{y}$ in the $x-$ and $y$-directions, respectively. In the $y$-direction, periodic boundary conditions are applied at $y=0$ and $y=L_{y}$. The longshore length $L_{y}$ is chosen equal to the wavelength of the fastest growing mode $(\sim 4 \mathrm{~km}$; Calvete and de Swart $(2003))$ in the case that slope $\beta$ has its present-day slope $\left(\sim 1 \cdot 10^{-3}\right)$. For larger (smaller) slopes $\beta$ this wavelength decreases (increases). Sensitivity of model results to different lengths $L_{y}$ will be examined as well (see section 2.3 .2 .

Before each experiment, the model is spun up until a hydrodynamic basic state is reached. Subsequently, at time $t=0$, the experiment starts by superimposing random perturbations (with amplitude of $\sim 2.0 \mathrm{~mm}$ ) on the initially flat bathymetry and switching on the sea level rise. In the default configuration, rate $R=1 \mathrm{~mm} / \mathrm{yr}$ but also other values of $R$ will be considered. The maximum simulation time is 10000 years.

The following characteristics of the ridges are of particular interest in the data analysis: their global growth and migration rates, their root-meansquare height and their crest orientation with respect to the coastline. The global growth rate $\sigma$ is defined, following Garnier et al. (2006), as

$$
\sigma \equiv \frac{1}{h_{r m s}^{2}} \frac{d}{d t} \frac{1}{2} h^{2} .
$$

In this expression, the overbar denotes averaging over the entire domain of the inner shelf (i.e. $\left.\frac{1}{\left(x_{i}-x_{s}\right) L_{y}} \int_{0}^{L_{y}} \int_{x_{i}}^{x_{s}} \cdot d x d y\right)$. The root-mean-square height is defined as 
The global migration rate (the migration rate with which the entire system ${ }^{271}$ migrates) is given by (Vis-Star et al., 2008)

$$
V_{m}=-\frac{1}{\overline{\left(\frac{\partial h}{\partial y}\right)^{2}}} \frac{\overline{\partial h} \frac{\partial h}{\partial y}}{\partial t} .
$$

The angle of orientation $(\theta)$ is defined as the angle between the ridge crest ${ }^{273}$ and the coastline $x=x_{c}$ (hereafter called 'coast'). ${ }^{274}$

Additionally, if the rising sea level causes the near-bed orbital velocity ${ }_{275}$ $u_{r m s}$ to drop below the critical velocity for erosion $u_{c}$, the variables $h_{r m s}{ }^{276}$ and $\theta$ are separately computed for the active part of the inner shelf (i.e. ${ }^{277}$ $x_{i}(t) \leq x \leq x_{d}(t)$, with $x_{d}(t)$ the cross-shore location at which $\left.u_{r m s}=u_{c}\right)$ as ${ }_{278}$ well as for its inactive part $\left(x_{d}(t)<x \leq x_{s}\right)$. The ridges in the latter part ${ }_{279}$ are drowned, i.e. their growth $\sigma$ and migration $V_{m}$ vanish. 280

\subsubsection{Sensitivity experiments ${ }_{281}$}

Experiments are conducted to examine the sensitivity of model results to 282 different rates of relative sea level rise in the range $[0.5-5] \mathrm{mm} / \mathrm{yr}$ (experi- ${ }^{283}$ ment 'SensRate1, table 1). Also, effects of using two different rates $R$ in one ${ }^{284}$ experiment (i.e. the rate at which the sea level rises varies with time) on 285 the characteristics of the ridges is investigated. In this experiment, between 286 $t=0$ and $t=5000$ years, rate $R=2.5 \mathrm{~mm} / \mathrm{yr}$, after which it decreases to ${ }^{287}$ $R=1 \mathrm{~mm} / \mathrm{yr}$ in the subsequent period $\left(R=[2.5 \rightarrow 1] \mathrm{mm} / \mathrm{yr}\right.$; experiment ${ }_{288}$ 'SensRate2'). Also, the sensitivity of model output to different landward ${ }^{289}$ 
water depths of the inner shelf (indicated by depth $H_{0}$ at the transition nearshore-zone inner shelf $x=x_{i}$ ) is studied. Values of $H_{0}$ range from $6 \mathrm{~m}$ to $18 \mathrm{~m}$. For each depth, three different fixed rates $(R=[1 ; 2.5 ; 5] \mathrm{mm} / \mathrm{yr})$ are used, as well as one mixed rate of sea level rise $(R=[2.5 \rightarrow 1] \mathrm{mm} / \mathrm{yr})$ (experiment 'SensDepth'). Finally, to verify robustness of model findings with respect to the initial width of the inner shelf $\left(L_{0}\right)$ and longshore lengths of the domain $\left(L_{y}\right)$, four additional experiments are conducted; first, one experiment in which a smaller value of $L_{0}$ is used $(=3 \mathrm{~km}$, experiment 'SensWidth') and the others where three different longshore lengths of the domain are imposed ( $L_{y}=3,6$ and $8 \mathrm{~km}$, experiment 'SensLength').

\section{Results}

\subsection{Default configuration}

Fig. 5 presents snapshots of the spatial distribution of bottom perturbations $h(x, y, t)$ in the $x$-y domain at times $t=0$ years (panel a, random bottom perturbations as initial conditions), $t=3000$ years (panel b), $t=6000$ years (panel c) and $t=9000$ years (panel d). During this period, the shoreface retreats over a distance of $\sim 2.8 \mathrm{~km}$ (panel e) and the shelf slope increases from 0 to $1.08 \times 10^{-3}$. Note that in this figure (for the sake of clarity), solutions for bottom perturbations $h(x, y, t)$, which are obtained in the domain of $\left(L_{x}-x_{i}\right) \times L_{y}$, are used to cover a domain with an alongshore length that is 4 times larger (i.e., $L_{y}=4 \times 4.1=16.4 \mathrm{~km}$ ). This latter can be done because of the periodic conditions applied at the lateral boundaries.

Clearly, bottom perturbations keep on growing with the rising seal level and the retreating shoreface. In the course of time (panels c,d), coast-oblique 
ridges (with an orientation $\theta$ in the range $\sim 40^{\circ}-50^{\circ}$ with the respect to 314 the coast) appear across the inner shelf. They extend from the retreating 315 landward side $\left(x=x_{i}\right)$ of the inner shelf until its seaward side $\left(x=x_{s}\right)$. ${ }_{316}$ Fig. 6a, which shows the time evolution of the root-mean-square height $h_{r m s}{ }_{317}$ of the ridges, reveals that the ridges reach a height of $\sim 1.4 \mathrm{~m}$ after 10000318 years. The present-day slope $\beta\left(\sim 1.1 \times 10^{-3}\right)$ is reached at $t \sim 9500$ years 319 (dashed grey line). 320 Initially $\left(t<3000\right.$ years), mode scale selection takes place (bottom per- ${ }^{321}$ turbations do not grow, i.e. $\sigma=0$ ), after which the most preferred mode 322 starts to grow at $t \sim 3000$ years (solid grey line in panel b). Height of bed- ${ }^{323}$ forms $h_{r m s}$ associated with this mode increases exponentially with a global 324 growth rate $\sigma$ of $\sim 5 \times 10^{-3} \mathrm{yr}^{-1}$. After $t \sim 5000$ years, strong nonlinear ${ }_{325}$ interactions occur resulting in a reduction of the growth rate. Fig. 6c further 326 demonstrates that the magnitude of the migration rate $V_{m}$ of the ridges de- ${ }_{327}$ creases to a value of $\sim 1 \mathrm{~m} \mathrm{yr}^{-1}$ between $t=3000$ years and $t=10000$ years. $\quad{ }^{328}$ Note the negative value of $V_{m}$, meaning that the ridges migrate in the neg- ${ }_{329}$ ative $y$-direction, i.e., the direction of the storm-driven current $\vec{v}$ (Fig. 5a). $\quad 330$ The angle of orientation $\theta$ decreases in the course of time (Fig. 6 $\mathrm{d}$ ). 331

\subsection{Sensitivity experiments 332}

3.2.1. Rate of sea level rise $R$

Results for higher rates $R$ of sea level rise (experiments 'SensRate1', Ta- ${ }_{334}$ ble 1) are presented in Fig. 7. It shows contour plots of height $h_{r m s}$, growth 335 rate $\sigma$, absolute value of migration rate $\left|V_{m}\right|$ and angle of orientation $\theta$ that 336 are constructed in the $R-t$ space, for both active (left panels) and drowned ${ }_{337}$ (right panels) ridges. Similar to the default case, active shore-oblique ridges 338 
appear, which have heights that increase with time (panel a). Panel e reveals that if rate $R \geq 1.5 \mathrm{~mm} / \mathrm{yr}$, drowned ridges also occur in the course time. Note that the increasing height of the latter ridges is due to the fact that with increasing sea level the drowning area (i.e. area in which $u_{r m s}<u_{c}$ ) increasingly covers the upper part of the inner shelf. Furthermore, it is seen that increasing $R$ leads to a larger growth of the active ridges, it speeds up their formation (panel b) as well as their drowning (panels $\mathrm{f}$ and $\mathrm{g}$ ) and it causes the magnitude of their migration rates to decline more rapidly with time (panel c). Interestingly, for all rates $R$, the times at which bottom perturbations start to grow (indicated by the solid grey line in panel b) correspond with a slope of $\sim 0.43 \times 10^{-3}$. Furthermore, from Fig. $7 \mathrm{~d}$,h, it appears that the angle of orientation $\theta_{\text {Drowned }}$ of the drowned ridges is approximately $8^{\circ}$ smaller than that of the active ones. This difference implies that the drowned ridges are oriented more parallel to the coast compared with active ones. As an example, Fig. 8 presents snapshots of how the spatial distribution of bottom perturbations $h(x, y, t)$ evolves in time in the case that sea level rises at a rate $R$ of $2.5 \mathrm{~mm} / \mathrm{yr}$. The orientation difference between active and drowned ridges can clearly be seen from panels c and d of this figure (indicated by dashed dotted lines).

Results of experiment 'SensRate2' (Table 1), in which $R$ varies during the simulation period $(R=2.5 \mathrm{~mm} / \mathrm{yr}$ for $t<5000$ years, followed by $R=1 \mathrm{~mm} / \mathrm{yr}$ for $t \geq 5000$ years ), are depicted in Fig. 9 (red lines). By way of comparison, results for two fixed rates, $R=1 \mathrm{~mm} / \mathrm{yr}$ (black lines) and $R=2.5 \mathrm{~mm} / \mathrm{yr}$ (blue lines) are included as well. Note that for $t<$ 5000 years, the blue and red lines are the same. Fig. 9a,b demonstrate that, 
after decreasing $R$ to $1 \mathrm{~mm} / \mathrm{yr}$ at $t=5000$ years, the increase in the height of 364 active and drowned ridges (red solid and dashed lines, respectively) reduces 365 compared with that in the case that $R$ would remain constant after this 366 time period (i.e. $R=2.5 \mathrm{~mm} / \mathrm{yr}$ for $t \geq 5000$ years, blue lines). Moreover, 367 panel $\mathrm{c}$ shows that in the former case, the reduction of migration rates of the ${ }_{368}$ active ridges is weaker after $t=5000$ years (red solid line) than that in the 369 latter case (blue solid line). Another noticeable difference between a fixed 370 an a mixed rate of sea level rise is that the angle of orientation of drowned 371 ridges decreases after decreasing rate $R$ at $t=5000$ years (red dashed line in 372 panel d), thereby further increasing the orientation difference between these 373 ridges and the active ones. $\quad 374$

\subsubsection{Landward depth $H_{0}$}

Sensitivity of model results with respect to smaller and larger landward 376 depths (indicated by depth $H_{0}$ at the transition $x=x_{i}$ between nearshore- ${ }^{377}$ zone inner shelf; experiment 'SensDepth', Table 1) is investigated in this 378 section. Results in the case of $R=1 \mathrm{~mm} / \mathrm{yr}$ are shown in Fig 10 . Here, 379 variables $h_{r m s}, \sigma,\left|V_{m}\right|$ and angle of orientation $\theta$ are constructed in the 380 $H_{0}-t$ space for both active (panels a-d) and drowned (panels e-h) ridges. 381 This figure reveals that an increasing depth $H_{0}$ leads to ridges with larger 382 heights (panel a), and it initiates their formation more rapidly (panels b). 383 Besides the more rapid formation of the ridges with increasing $H_{0}$, the time 384 period of this formation lasts also longer. In the case of large $H_{0}(=16 \mathrm{~m}, \quad 385$ $18 \mathrm{~m}$ ) the ridges drown in the course of time (Fig 10?). If the landward 386 depth is too small $\left(H_{0}<11 \mathrm{~m}\right.$, grey area), active ridges do not form. No 387 drowned ridges are observed if depth $H_{0}<16 \mathrm{~m}$ and $R=1 \mathrm{~mm} / \mathrm{yr}$. With ${ }_{388}$ 
increasing depth $H_{0}$, the magnitude of the migration rate $V_{m}$ of active ridges declines more rapidly in the course of time (Fig 10c). Also, in the case of the formation of drowned ridges $\left(H_{0} \geq 16 \mathrm{~m}\right)$, an orientation difference $\Delta \theta$ between the latter (panel $\mathrm{h}$ ) and the active (panel $\mathrm{d}$ ) ridges is induced, which implies that the drowned ridges are orientated more parallel to the coast compared with the active ones.

A new feature revealed by experiment 'SensDepth' (Fig. 11) is that in the case of a landward depth $H_{0}$ of $11 \mathrm{~m}$ and using a mixed rate of sea level rise $([2.5 \rightarrow 1] \mathrm{mm} / \mathrm{yr})$, the drowned offshore parts detach from the active onshore ones at $t \sim 8000$ years (panel b) to form a series of inactive ridges on the shelf floor in the subsequent time period (panels c, d). From Fig. 12a, it is found that the active onshore parts experience larger migration rates in the case of a smaller landward depth (red solid line) compared with those in the case of a larger depth (blue solid line). In the end, the inactive ridges and the attached ones ( $\mathrm{sfcr}$ ) have an orientation difference of $\sim 20^{0}$ with respect to the coast Fig. $12 \mathrm{~b}$.

\subsubsection{Initial shelf width $L_{0}$ and longshore domain length $L_{y}$}

Model results for a smaller initial width of the inner shelf $\left(L_{0}=3 \mathrm{~km}\right.$, experiment 'SensWidth', Table 1) are presented in the Electronic Supplement (Fig. E1). This figure shows a qualitatively similar behavior in the former case compared with that in the default case, i.e. active ridges appear on the inner shelf (panels a and b of Fig. E1) with heights that increase and migration rates that decrease in time (panel c). The main quantitative differences between experiments 'Default' and 'SensWidth', are that in the latter case, the formation of the ridges is faster, their growth is stronger (red lines in 
panels $\mathrm{a}$ and $\mathrm{b}$ ), the decline in the magnitude of their migration rates is ${ }_{414}$ weaker (red lines in panel c), and the angle of their orientation with respect ${ }^{415}$ to the coast is slightly higher (red lines in panel d) than those in the former ${ }_{416}$ case.

With regard to the sensitivity of model results to different longshore ${ }_{418}$ lengths of the domain (experiment SensLength', Table 1), the results do not ${ }_{419}$ fundamentally differ from those of the default case (Fig. E2 in the Electronic ${ }_{420}$ Supplement). With increasing shelf length $L_{y}$, ridges have larger heights ${ }^{421}$ (panel a), they emerge faster (panel b), their migration is smaller (panel c) ${ }_{422}$ and the decrease in the angle of their orientation with time is smaller. ${ }^{423}$

\section{Discussion}

424

An important result revealed by the model is that a drowned (i.e. van- ${ }^{425}$ ishing growth and migration) offshore part of a ridge is aligned more parallel ${ }_{426}$ to the coast compared with its active onshore part. Furthermore, in the case ${ }_{427}$ of a small landward depth of the inner shelf and a decreasing rate of sea ${ }_{428}$ level rise with time, an orientation difference between the active onshore and ${ }_{429}$ drowned offshore parts of the ridges was found. Besides, the latter parts ${ }_{430}$ also detach from the former ones to form a field of inactive bedforms. This ${ }_{431}$ section addresses the physical mechanisms responsible for these properties. $\quad{ }^{432}$

\subsection{Orientation difference and detachment ${ }_{433}$}

A conceptual model for the change in the orientation and detachment of ${ }_{434}$ an offshore ridge is presented in Fig. 13. As the sea level rises, the near- ${ }_{435}$ bed orbital velocity $u_{r m s}$ decreases. In the course of time, orbital velocity ${ }_{436}$ $u_{r m s}$ will be below the critical velocity for erosion $u_{c}$ in an offshore part of ${ }_{437}$ 
the inner shelf (grey area in Fig. 13) that extends towards the coast with increasing sea level. As the migration of the offshore part of the ridge in this area vanishes, this part of the ridge (dashed red lines) lags behind the more onshore part (solid red lines) of the ridge, which meanwhile keeps on migrating in the downstream direction. This process continues in the course of time at the location where $u_{r m s}=u_{c}$ (Fig. 13 , panels c,d).

As was demonstrated by Nnafie et al. (2014), the migration of bedforms scales as $V_{m} \sim\left(\widetilde{U}_{r m s}^{2}-u_{c}^{2}\right) /\left(\widetilde{U}_{r m s} \widetilde{H}\right)$, with $\widetilde{H}$ and $\widetilde{U}_{r m s}$ typical values of the width and depth of the inner shelf and of the near-bed wave orbital velocity, respectively. This velocity scale demonstrates that bedforms migrate faster in the case of smaller landward depths of the inner shelf (and consequently larger $\widetilde{U}_{r m s}$ ) than in the case of larger depths. Thus, in the former case, a larger differential migration rate exists between the drowned and active parts of the ridge than those in the latter case. If the differential migration rate is too large, as in the case of a landward depth $H_{0}$ of $11 \mathrm{~m}$, the drowned offshore parts of the ridges can not maintain their attachment to the active onshore parts. Consequently, the former parts detach from the latter ones to become inactive sand ridges that are oriented more parallel to the coast compared with ridges that are still attached to the shoreface (sfcr). Such an event appears particularly in the case that the rate of sea level rise decreases in the course of time. This is because a smaller rate (and consequently a weaker steepening and a smaller widening of the inner shelf) reduces the decrease in the migration of the active onshore part of the ridge, thereby creating a larger differential migration rate between this part and the drowned offshore part. 
4.2. Shelf steepening 463

With respect to the preceding paper of Nnafie et al. (2014), where no ${ }_{464}$ bending and detachment of ridges were found in the case that rate of sea ${ }_{465}$ level rise is $1 \mathrm{~mm} / \mathrm{yr}$, the question rises whether the simultaneous sim- 466 ulation of the steepening of the shelf and the shoreface retreat is a ne- ${ }^{467}$ cessity to reach the bending and detachment of the drowned ridges. For ${ }_{468}$ this, additional experiments were conducted with the model of Nnafie et al. ${ }_{469}$ (2014), which does not account for shelf steepening, for three different slopes 470 $\left(\beta=[0.40 ; 0.75 ; 1.0] \times 10^{-3}\right)$ where the landward depth $H_{0}=11 \mathrm{~m}$ and ${ }_{471}$ $R=[2.5 \rightarrow 1] \mathrm{mm} / \mathrm{yr}$ were chosen. Bending of the offshore part of the ridge ${ }_{472}$ occurred in all these experiments, but detachment was observed only in the ${ }_{473}$ case of $\beta=0.75 \times 10^{-3}$. These results indicate that steepening of the shelf, ${ }_{474}$ albeit causing differential migration speeds of sfcr because of reasons pre- ${ }^{475}$ sented in section 1, is not crucial for bending and detachment of the offshore 476 part of the ridges.

\subsection{Comparison with field observations 478}

Observed sfcr have an oblique orientation with respect to the coast (typ- ${ }_{479}$ ical orientation $\sim 30-50^{\circ}$, Schwab et al., 2013), whereas further seaward, 480 sand ridges are in general more coast-parallel (Swift and Freeland, 1978, Stub- ${ }^{481}$ blefield et al., 1984). Furthermore, sand ridges are asymmetric, with steeper ${ }_{482}$ (milder) seaward (landward) flanks. In general, with increasing depth, ridges ${ }^{483}$ are higher and they become increasingly asymmetric (Swift and Field, 1981; ${ }_{484}$ Stubblefield et al., 1984; Goff and Duncan, 2012).

In the case of a decreasing rate of sea level rise with time and a small ${ }_{486}$ depth of the landward part of the inner shelf $(\sim 11 \mathrm{~m})$, the model simulates ${ }_{487}$ 
a field of shore-oblique $\left(\theta \sim 40^{\circ}\right)$ attached and more shore-parallel $\left(\theta \sim 20^{\circ}\right)$ inactive sand ridges in shallow and deep waters, respectively. Fig. 14, which shows snapshots of the alongshore profiles of bottom perturbations $h$ at two different cross-shore locations $(x=-2 \mathrm{~km}$, blue line; $x=5 \mathrm{~km}$, red line) demonstrates that ridge heights are larger in the deep part of the inner shelf compared with those in the shallow part. Moreover, from this figure it is seen that ridges are steepest on their seaward flanks, and that their offshore parts have steeper seaward flanks than onshore ones. These model findings are in qualitative agreement with field observations. It should be stressed that this model is a gross simplification of reality (Section 4.4) and, thus, such a comparison is not straightforward. In reality, the geometry of the continental shelf such as that of Long Island and the observed patterns of the ridges are quite complex

citepschwab2013,schwab2014. Many ridges are characterized by the presence of small-scale bottom features, with wavelengths in the order of a few hundreds meters. Furthermore, these ridges may be connected to a nearshore bar system (Schwab et al., 2000). This suggests that other mechanisms, besides those included in the model, may play a role. Additionally, the applied scenarios of shelf evolution in response to rising sea level and retreating shoreface are highly idealized. In reality, shelf and coastal morphological changes result from the interaction of a complex array of processes and mechanisms acting over a variety of time and space scales. Nevertheless, it is encouraging to see that this model, which yields comparable rates of shoreface retreat as those observed (order of meters per year, McBride and Moslow, 1991, Hapke et al., 2011, captures well some mean characteristics (such as height 
and asymmetry) of the observed shelf ridges. Moreover, the model is capable 513 of simulating shore-oblique shoreface-connected and more parallel offshore ${ }_{514}$ located sand ridges. $\quad 515$

\subsection{Model simplifications 516}

The present model is based on several assumptions. The major simpli- ${ }_{517}$ fications are described below. Other simplifications are discussed in Nnafie 518 et al. (2014).

First, the model that describes the landward migration and steepening 520 of the inner shelf in response to rising sea level (Eq. 3) is highly idealized. ${ }_{521}$ In reality, shelf and coastal morphological changes result from the interac- ${ }_{522}$ tion of a complex array of processes and mechanisms acting over a variety of ${ }_{523}$ temporal and spatial scales. The shelf slope is primarily a function of the an- ${ }^{524}$ tecedent stratigraphy being eroded by the processes associated with marine ${ }^{525}$ transgression. Sediment eroded from the shoreface during transgression does ${ }_{526}$ not form a sheet of sand offshore, as is the case of the scenarios considered ${ }_{527}$ in this study (Fig. 3). Furthermore, the definition of the offshore ridge orien- ${ }_{528}$ tations is relative to the modern shoreline position, which may be different ${ }_{529}$ than the shoreline position when those ridges were formed. Another aspect 530 to mention is that there are observations of cross-shore sediment transport ${ }_{531}$ processes (e.g. offshore directed storm-driven undertow during stormy con- 532 ditions (Niedoroda et al., 1984; Hayes and Nairn, 2004)) that can transport ${ }_{533}$ sediment from the nearshore zone to less active regions located far offshore. ${ }_{534}$ This sediment transport will increase the morphodynamic activity of drowned 535 ridges that are located in the latter areas. $\quad 536$ Secondly, effects of the changing seafloor on wave characteristics (wave- ${ }^{537}$ 
topography feedbacks) are not accounted for in the present study. Vis-Star et al. (2007) and Nnafie et al. (2011), who used a wave transformation model that is based on linear wave theory (as in the present model), showed that the inclusion of these feedbacks causes enhanced wave stirring in the area upstream of the ridges due to focusing of wave rays in this area. As a consequence, the ridges grow and migrate too fast, which might be due to neglecting directional spreading of waves in these models. To account properly for these feedbacks, a spectral wave model, (e.g., SWAN,Holthuijsen, 2007) would be required.

Thirdly, in observational studies it is stressed that storms are highly episodic events (Lentz et al., 2013). In this study the formation and evolution of the ridges is investigated for continuous stormy conditions, where the underlying assumption is that morphodynamic activity of the ridges mainly takes place during storms, whereas during fair weather conditions it is assumed that there is hardly any activity. In reality wave asymmetry might also cause onshore sediment transport during fair weather conditions (Hayes and Nairn, 2004). Furthermore, storms will involve different wind intensities and directions. Within the context of the present study, a changing storm and wave climate would imply that the drowned offshore parts during mild stormy conditions will become active during severe storms. This would cause irregularities in the growth, migration and orientation of the ridges.

\section{Conclusions}

The main aim of this study was to understand the observed orientation difference between shoreface-connected sand ridges and the more offshore lo- 
cated ridges. For this, the model of Nnafie et al. (2014) was modified by 562 implementing an equilibrium beach profile equation that allows a simultane- 563 ous simulation of steepening of the inner shelf and shoreface retreat under a 564 rising sea level. Various scenarios were considered, in which different rates 565 of sea level rises and different landward depths of the inner shelf were used 566 to systematically explore their effects on the characteristics (growth rate, ${ }_{567}$ height, migration, orientation) of sand ridges on an inner shelf. 568

For a model setting that resembles the Long Island inner shelf, results 569 show that coast-oblique ridges appear in the shallow part of the inner shelf, 570 which remain active in time (i.e. ongoing growth and migration). Ridges, 571 initially formed in shallow waters, become located progressively further sea- $\quad 572$ ward due the retreating shoreface and the rising sea level. In the course of ${ }_{573}$ time these ridges become decreasingly active until they eventually drown, 574 i.e. their growth and migration vanish. In addition, higher rates and larger 575 landward depths induce an orientation difference between the active onshore $\quad 576$ and drowned offshore parts of the ridges, such that the latter parts are ori- 577 ented more parallel to the coast compared with the onshore ones. This is 578 due to the fact that the drowned offshore parts of the ridges lag behind the ${ }_{579}$ more onshore ones, which meanwhile keep on migrating in the downstream 580 direction. If this differential migration rate is too large, as in the case of a 581 decreasing rate of sea level rise with time and a shallow landward part of 582 the inner shelf, the drowned offshore parts cannot maintain their attachment $\quad 583$ to the active onshore parts (sfcr). As a result, the former parts detach and ${ }_{584}$ strand on the shelf floor to become inactive. The simulated field of shore- 585 oblique shoreface-connected sand ridges and more parallel offshore located 586 
ones is in qualitative agreement with observations.

Further analysis revealed that the simultaneous simulation of the steepening of the shelf and the shoreface retreat is not a necessity to reach the detachment of the ridges. Bending and detachment of ridges are mainly the effect of a decrease in rate of sea level rise over time and a shallow landward part of the inner shelf.

\section{Acknowledgements}

This work is part of the research programme: Effect of self-organisation, interventions, sea level rise and storm chronology on the nonlinear dynamics of shoreface-connected sand ridges (NWO-ALW, grant BOC21), which is financed by the Netherlands Organization for Scientific Research (NWO).

\section{References}

Barrie, J.V., Conway, K.W., 2013. Seabed characterization for the development of marine renewable energy on the Pacific margin of Canada. Continental Shelf Research doi:10.1016/j.csr.2013.10.016.

Calvete, D., Falqués, A., de Swart, H.E., Walgreen, M., 2001. Modelling the formation of shoreface-connected sand ridges on storm-dominated inner shelves. Journal of Fluid Mechanics 441, 169-193.

Calvete, D., de Swart, H.E., 2003. A nonlinear model study on the longterm behavior of shoreface-connected sand ridges. Journal of Geophysical Research 108, 3169. doi:10.1029/2001JC001091. 
608

Cowell, P.J., Stive, M.J., Niedoroda, A.W., Swift, D.J., de Vriend, H.J., Buijsman, M.C., Nicholls, R.J., Roy, P.S., Kaminsky, G.M., Cleveringa, ${ }^{609}$ J., et al., 2003. The coastal-tract (part 2): Applications of aggregated ${ }_{610}$ modeling of lower-order coastal change. Journal of Coastal Research 19, ${ }_{611}$ $828-848$.

Dean, R.G., 1987. Coastal sediment processes: Toward engineering solutions, ${ }_{613}$ in: Coastal Sediments (1987), American Society of Civil Engineers. pp. 1- ${ }^{614}$ 24 .

Duane, D.B., Field, M.E., Meisburger, E.P., Swift, D.J., Williams, S.J., 1972. ${ }_{616}$ Linear shoals on the Atlantic inner continental shelf, Florida to Long Is- ${ }_{617}$ land. In: Shelf Sediment Transport: Process and Pattern, edited by D. J. ${ }_{618}$ P. Swift, D. B. Duane, and O. H. Pilkey; Dowden, Hutchinson and Ross, ${ }_{619}$ Stroudsburg , 447-498.

Dyer, K.R., Huntley, D.A., 1999. The origin, classification and modelling of ${ }_{621}$ sand banks and ridges. Continental Shelf Research 19, 1285-1330. 622

Engelhart, S., Peltier, W., Horton, B., 2011. Holocene relative sea-level ${ }_{623}$ changes and glacial isostatic adjustment of the US Atlantic coast. Geology ${ }^{624}$ $39,751-754$.

625

Garnier, R., Calvete, D., Falqués, A., Caballeria, M., 2006. Generation and ${ }^{626}$ nonlinear evolution of shore-oblique/transverse sand bars. Journal of Fluid ${ }_{627}$ Mechanics 567, 327-360.

628

Goff, J.A., Duncan, L.S., 2012. Re-examination of sand ridges on the mid- ${ }_{629}$ dle and outer New Jersey shelf based on combined analysis of multi- ${ }^{630}$ 
beam bathymetry and backscatter, seafloor grab samples and chirp seismic ${ }_{631}$ data. Sediments, Morphology and Sedimentary Processes on Continental Shelves: Advances in Technologies, Research, and Applications 44, 121142.

Goff, J.A., Swift, D.J.P., Duncan, C.S., Mayer, L.A., Hughes-Clarke, J., 1999. High-resolution swath sonar investigation of sand ridge, dune and ribbon morphology in the offshore environment of the New Jersey margin. Marine Geology 161, 307-337.

Hapke, C.J., Himmelstoss, E.A., Kratzmann, M.G., List, J.H., Thieler, E., 2011. National assessment of shoreline change; historical shoreline change along the New England and Mid-Atlantic coasts. Technical Report. U. S. Geological Survey, Open File Report 2010-1118, 57p.

Hapke, C.J., Lentz, E.E., Gayes, P.T., McCoy, C.A., Hehre, R., Schwab, W.C., Williams, S.J., 2010. A review of sediment budget imbalances along Fire Island, New York: Can nearshore geologic framework and patterns of shoreline change explain the deficit? Journal of Coastal Research 26, $510-522$.

Hayes, M.O., Nairn, R.B., 2004. Natural maintenance of sand ridges and linear shoals on the US Gulf and Atlantic continental shelves and the potential impacts of dredging. Journal of Coastal Research 20, 138-148.

van Heteren, S., van der Spek, A., van der Valk, B., 2011. Evidence and implications of middle-to late-Holocene shoreface steepening offshore the western Netherlands, in: Proceedings Coastal Sediments, pp. 188-201. 
654

Holthuijsen, L.H., 2007. Waves in oceanic and coastal waters. Cambridge University Press.

Hutton, E.W., Syvitski, J.P., Watts, A., 2013. Isostatic flexure of a finite ${ }_{656}$ slope due to sea-level rise and fall. Computers \& Geosciences 53, 58-68. ${ }_{657}$

Lentz, E.E., Hapke, C.J., Stockdon, H.F., Hehre, R.E., 2013. Improving 658 understanding of near-term barrier island evolution through multi-decadal ${ }_{659}$ — assessment of morphologic change. Marine Geology 337, 125-139. doi:10 . ${ }_{660}$ 1016/j.margeo.2013.02.004.

Masetti, R., Fagherazzi, S., Montanari, A., 2008. Application of a barrier ${ }_{662}$ island translation model to the millennial-scale evolution of Sand Key, ${ }_{663}$ Florida. Continental Shelf Research 28, 1116-1126.

McBride, R.A., Moslow, T.F., 1991. Origin, evolution, and distribution of ${ }_{665}$ shoreface sand ridges, Atlantic inner shelf, USA. Marine Geology 97, 57- ${ }_{666}$ 85.

McClennen, C.E., McMaster, R.L., 1971. Probable Holocene transgressive ${ }_{668}$ effects on the geomorphic features of the continental shelf off New Jersey, ${ }_{669}$ United States. Maritime Sediments 7, 69-72.

Niedoroda, A.W., Reed, C.W., Swift, D.J., Arato, H., Hoyanagi, K., 1995. 671 Modeling shore-normal large-scale coastal evolution. Marine Geology 126, 672 $181-199$.

Niedoroda, A.W., Swift, D.J.P., Hopkins, T.S., Ma, C.M., 1984. Shoreface 674 morphodynamics on wave-dominated coasts. Marine Geology 60, 331-354. 675 
Nnafie, A., de Swart, H.E., Garnier, R., Calvete, D., 2011. Formation 676 of shoreface-connected sand ridges: effects of rigid-lid approach, quasi- 677 steady approach and wave-topography feedbacks, in: Proceedings of the 7th IAHR Symposium on River, Coastal and Estuarine Morphodynamics: RCEM2011, Tsinghua University Press, Beijing, pp. 2114-2123.

Nnafie, A., de Swart, H.E., Garnier, R., Calvete, D., 2014. Effects of sea level rise on the formation and drowning of shoreface-connected sand ridges, a model study. Continental Shelf Research 80, 32-48. doi:10.1016/j.csr. 2014.02.017.

NOAA, 2013. National Geophysical Data Center, U.S. Coastal Relief Model. http://www.ngdc.noaa.gov/mgg/coastal/crm.html.

Panageotou, W., Leatherman, S.P., 1986. Holocene-Pleistocene stratigraphy of the inner shelf off Fire Island, New York: Implications for barrier-island migration. Journal of Sedimentary Research 56, 528-537.

Rampino, M.R., Sanders, J.E., 1980. Holocene transgression in south-central Long Island, New York. Journal of Sedimentary Research 50, 1063-1079.

Schwab, W.C., Baldwin, W.E., Denny, J.F., Hapke, C.J., Gayes, P.T., List, J.H., Warner, J.C., 2014. Modification of the quaternary stratigraphic framework of the inner-continental shelf by holocene marine transgression: an example offshore of Fire Island, New York. Marine Geology 355, 346360.

Schwab, W.C., Baldwin, W.E., Hapke, C.J., Lentz, E.E., Gayes, P.T., Denny, J.F., List, J.H., Warner, J.C., 2013. Geologic evidence for onshore sediment 
699

transport from the inner continental shelf: Fire Island, New York. Journal of Coastal Research 29, 526-544. doi:10.2112/JCOASTRES-D-12-00160.1. 700

Schwab, W.C., Thieler, E.R., Allen, J.R., Foster, D.S., Swift, B.A., Denny, 701 J.F., 2000. Influence of inner-continental shelf geologic framework on the 702 evolution and behavior of the barrier-island system between Fire Island ${ }_{703}$ Inlet and Shinnecock Inlet, Long Island, New York. Journal of Coastal 704

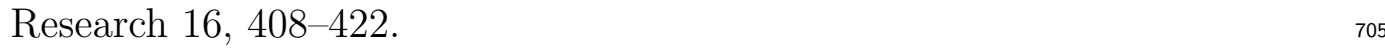

Snedden, J.W., Tillman, R.W., Culver, S.J., 2011. Genesis and evolution 706 of a mid-shelf, storm-built sand ridge, New Jersey continental shelf, USA. ${ }^{707}$ Journal of Sedimentary Research 81, 534-552. 708

Stubblefield, W.L., McGrail, D.W., Kersey, D.G., 1984. Recognition of trans- 709 gressive and post-transgressive sand ridges on the New Jersey continental 710 shelf. Special Publication of the Society of Economic Paleontologists and 711

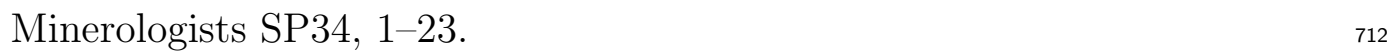

Swift, D.J., Duane, D.B., McKinney, T.F., 1973. Ridge and swale topography 713 of the Middle Atlantic Bight, North America: Secular response to the 714 Holocene hydraulic regime. Marine Geology 15, 227-247. 715

Swift, D.J., Freeland, G.L., 1978. Current lineations and sand waves on the 716 inner shelf, Middle Atlantic Bight of North America. Journal of Sedimen- ${ }_{717}$ tary Research 48, 1257-1266. 718

Swift, D.J.P., Field, M.E., 1981. Evolution of a classic sand ridge field: 719 Maryland sector, North American inner shelf. Sedimentology 28, 461-482. 720 
Swift, D.J.P., Parker, G., Lanfredi, N.W., Perillo, G., Figge, K., 1978. 721 Shoreface-connected sand ridges on American and European shelves: a ${ }_{722}$

723 comparison. Estuarine and Coastal Marine Science 7, 257-273.

Trowbridge, J.H., 1995. A mechanism for the formation and maintenance of shore-oblique sand ridges on storm-dominated shelves. Journal of Geophysical Research 100, 16071-16086.

Vis-Star, N.C., de Swart, H.E., Calvete, D., 2007. Effect of wave-topography interactions on the formation of sand ridges on the shelf. Journal of Geophysical Research 112, 1978-2012. doi 10.1029/2006JC003844.

Vis-Star, N.C., de Swart, H.E., Calvete, D., 2008. Patch behaviour and predictability properties of modelled finite-amplitude sand ridges on the inner shelf. Nonlinear Processes in Geophysics 15, 943-955.

Warner, J.C., List, J.H., Schwab, W.C., Voulgaris, G., Armstrong, B., Marshall, N., 2014. Inner-shelf circulation and sediment dynamics on a series of shoreface-connected ridges offshore of Fire Island, NY. Ocean Dynamics 64, 1767-1781. doi:10.1007/s10236-014-0781-y. 


\section{List of Figures}

$1 \quad$ Bathymetric map of the Long Island continental shelf. Insert 738 on top left: large scale map. Active shore-oblique sand ridges (sfcr) are located in shallow waters offshore of Fire Island. Further seaward (indicated by the white 20m-isobath), more shore-parallel sand ridges are observed. According to Goff et al. [1999), beyond a depth of $\sim 20 \mathrm{~m}$ sand ridges become less active. Map based on data from $\operatorname{NOAA}[(2013) . \quad$. . . . . 36

$2 \quad$ Schematic view of the study area. For an explanation of the 745 symbols see the text. . . . . . . . . . . . . $377_{746}^{74}$

\begin{tabular}{|lll}
3 & Schematic view of the change of the coastal zone geometry & 747 \\
747
\end{tabular} under sea level rise within a small time increment $\Delta t$, under ${ }_{748}^{747}$ \begin{tabular}{|c|}
7 \\
\hline \hline
\end{tabular} 49

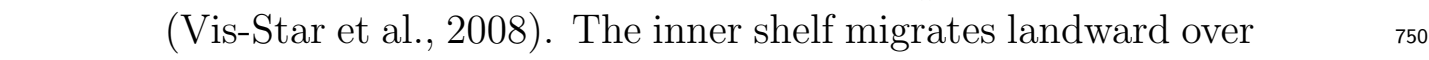
a distance $\Delta x_{i}\left(=x_{i}(t+\Delta t)-x_{i}(t)\right)$ while its slope $\beta$ increases. 751 \begin{tabular}{|l|l|}
752 & \\
\hline The location of the transition inner-outer shelf $\left(x_{s}\right)$, the depth &
\end{tabular} $H_{i}\left(=H_{0}\right)$ at the transition nearshore zone-inner shelf $\left(x=x_{i}\right) \quad 753$ and the width $w\left(=x_{i}-x_{c}\right)$ of the nearshore zone are kept fixed. $38 \quad 754$ \begin{tabular}{l|ll|}
4 & Rate of shoreface retreat $d x_{i} / d t$ (panel a) and bottom slope $\beta$ &
\end{tabular} 75 (panel b) in the $R-t$ space in the case of present-day values 756 of the shelf (Section 2.3.1).................. 39757

$5 \quad$ (a-d) Snapshots of the spatial distribution of bottom pertur- 758 bations $h(x, y, t)(\mathrm{m})$ in the $x$ - $y$ domain for the default case $\quad 759$ $\left(H_{0}=14 \mathrm{~m}\right.$ and $\left.R=1 \mathrm{~mm} / \mathrm{yr}\right)$ at times $t=0$ years (panel a), $\quad 760$ $t=3000$ years (panel b), $t=6000$ years (panel c), and 761 $t=9000$ years (panel d). Crests and troughs are indicated 762 by red and blue colors, respectively. Dashed black lines in- 763 dicate location of the initial transition nearshore zone-inner 764 shelf $\left(x_{i}=0\right)$ and solid black lines denote that of the new 765 transition $\left(x_{i}\right)$. The part of the domain that is not yet part of ${ }_{766}$ the inner shelf is indicated by grey. The black arrows in panel 767 (a) indicate directions of storm-driven current and waves. (e) 768 Cross-shore profile of mean bed level $\left\langle z_{b}\right\rangle$ at $t=9000$ years. . . 40 
770

6 (a) The root-mean-square height $h_{r m s}$ of the sand ridges averaged over the entire inner shelf (i.e. $x_{i} \leq x \leq x_{s}$ ), which remains active during the full simulation time period of 10000 years. (b) As in (a), but for the global growth rate $\sigma$. (c) As in (a), but for the global migration rate $V_{m}$. (d) As in (a), but for the angle of orientation $\theta$ of the ridges with respect to the coast. Variables $V_{m}$ (panel c) and $\theta$ (panel d) are computed from the time $(t \sim 3000$ years, solid grey vertical lines $)$ when bottom perturbations $h$ start to grow $(\sigma>0)$. In panel a, the dashed grey line indicates the time $(\sim 9500$ years $)$ at which the slope $\beta$ has its present-day value $\left(\sim 1.1 \times 10^{-3}\right) . \ldots$. . . . . . . 41 7 Left (a-d): Contour plots of (a) height $h_{r m s, \text { Active }}$, (b) growth rate $\sigma_{\text {Active }},(\mathrm{c})$ absolute value of migration rate $V_{m, \text { Active }}$ and (d) angle of orientation $\theta_{\text {Active }}$ of the active ridges in the $R-t$ space (experiment 'SensRate1', Table 1). Right (e-h): As in the left panels, but for drowned ridges. The dashed grey line in panel a denotes the times at which the slope $\beta$ has its presentday value $\left(\sim 1.1 \times 10^{-3}\right)$. In area 'A', active ridges have not yet appeared $(\sigma \leq 0)$. In area 'C', drowned ridges are not observed yet $\left(u_{r m s}>u_{c}\right.$, with $\left.u_{c}=0.35 \mathrm{~m} / \mathrm{yr}\right)$, and in the grey area, they do not appear during the entire simulation period. In area 'B', no solutions were obtained with the model. 42

8 As in Fig. 5 , but for a higher rate $R$ of $2.5 \mathrm{~mm} / \mathrm{yr}$. In panels $c$ and $d$, the dashed dotted lines indicate the orientation of active and drowned ridges with respect to the coast. The dashed white lines mark the transition between the drowned and active part of the inner shelf $\left(u_{r m s}=u_{c}\right)$. . . . . . . .

$9 \quad$ As in Fig. 6 (black lines), but including results for a mixed rate (red lines; $R=[2.5 \rightarrow 1] \mathrm{mm} / \mathrm{yr}$, i.e. $R=2.5 \mathrm{~mm} / \mathrm{yr}$ for $t<$ 5000 years and $R=1 \mathrm{~mm} /$ yr for $t \geq 5000$ years, experiment 'SensRate2', Table 1) and a fixed rate $R=2.5 \mathrm{~mm} / \mathrm{yr}$ (blue lines). Solid and dashed lines represent active and drowned ridges, respectively. Note that for $t<5000$ years, the blue and red lines are the same. . . . . . . . . . . . . . . 44 10 (a-h): As in Fig. 77, but in the $H_{0}-t$ space (experiment 'SensDepth', Table 1). In the grey areas in the left panels, active ridges do not form, and in those in the right panels ridges do not drown. Rate of sea level rise $R=1 \mathrm{~mm} / \mathrm{yr}$. . . . . . . . . 458 


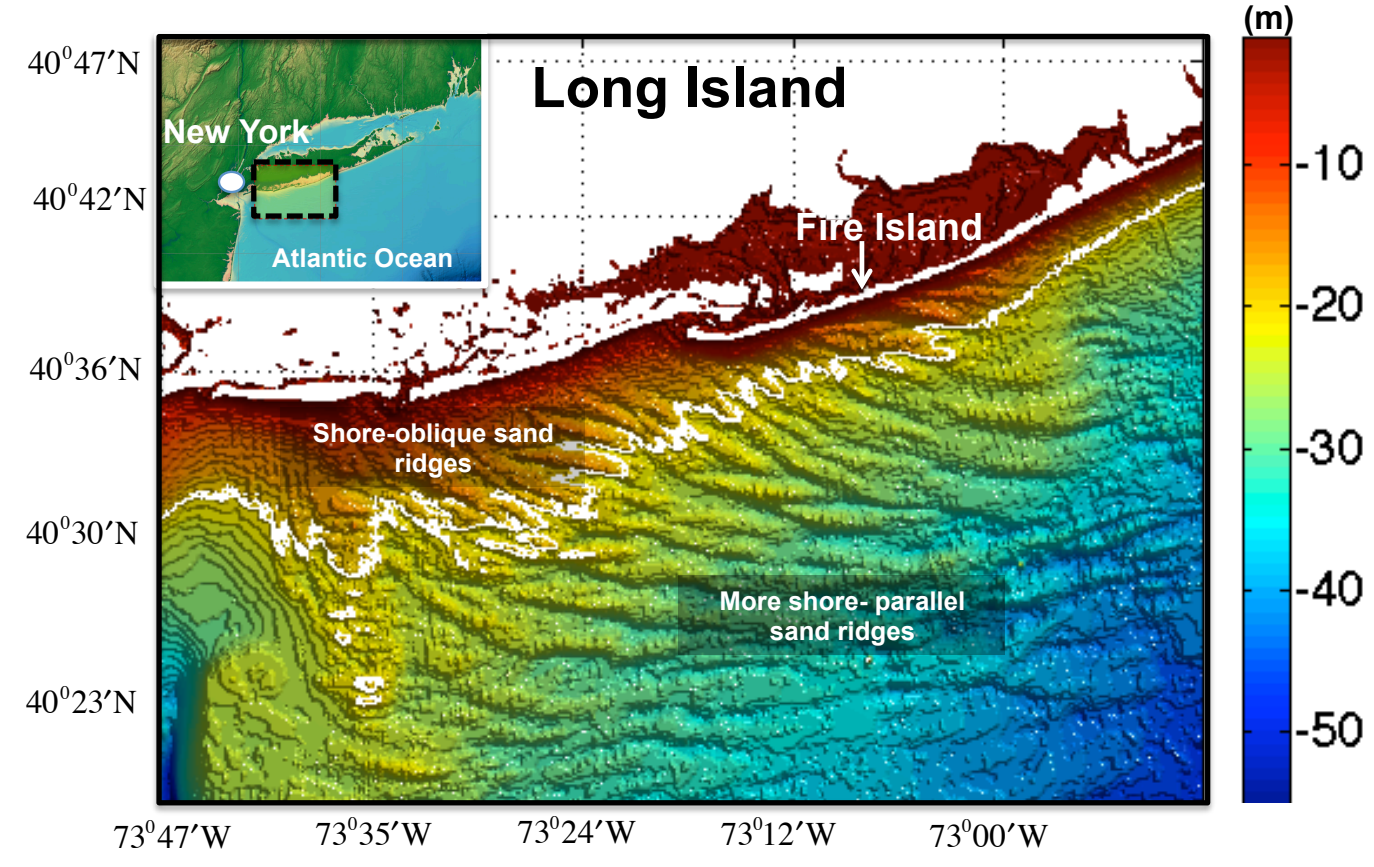

Figure 1: Bathymetric map of the Long Island continental shelf. Insert on top left: large scale map. Active shore-oblique sand ridges (sfcr) are located in shallow waters offshore of Fire Island. Further seaward (indicated by the white 20m-isobath), more shore-parallel sand ridges are observed. According to Goff et al. (1999), beyond a depth of $\sim 20 \mathrm{~m}$ sand ridges become less active. Map based on data from NOAA (2013). 


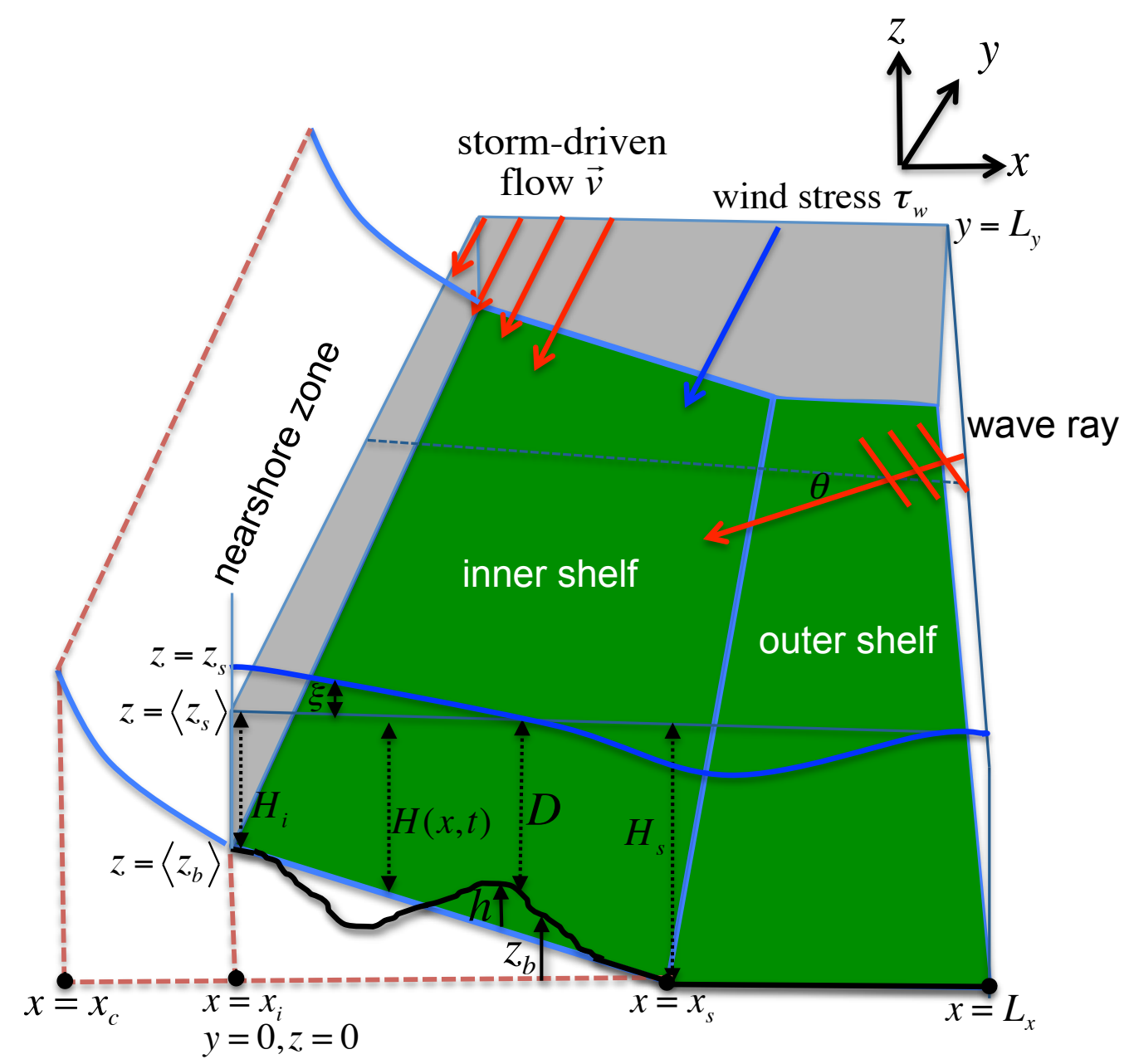

Figure 2: Schematic view of the study area. For an explanation of the symbols see the text. 


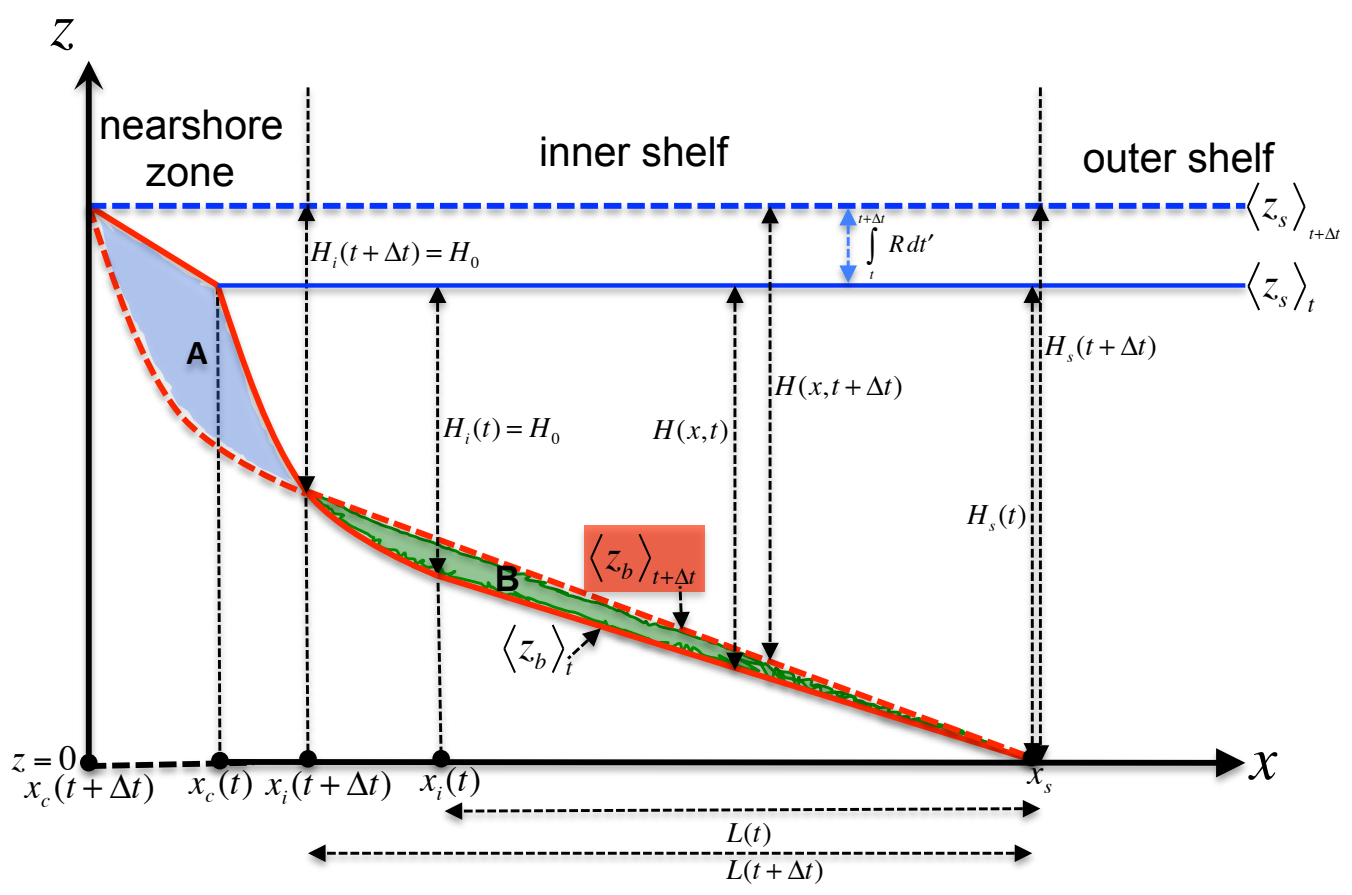

Figure 3: Schematic view of the change of the coastal zone geometry under sea level rise within a small time increment $\Delta t$, under the condition that sand volume in area $\mathrm{A}$ equals that in area B (Vis-Star et al., 2008). The inner shelf migrates landward over a distance $\Delta x_{i}\left(=x_{i}(t+\Delta t)-x_{i}(t)\right)$ while its slope $\beta$ increases. The location of the transition innerouter shelf $\left(x_{s}\right)$, the depth $H_{i}\left(=H_{0}\right)$ at the transition nearshore zone-inner shelf $\left(x=x_{i}\right)$ and the width $w\left(=x_{i}-x_{c}\right)$ of the nearshore zone are kept fixed. 

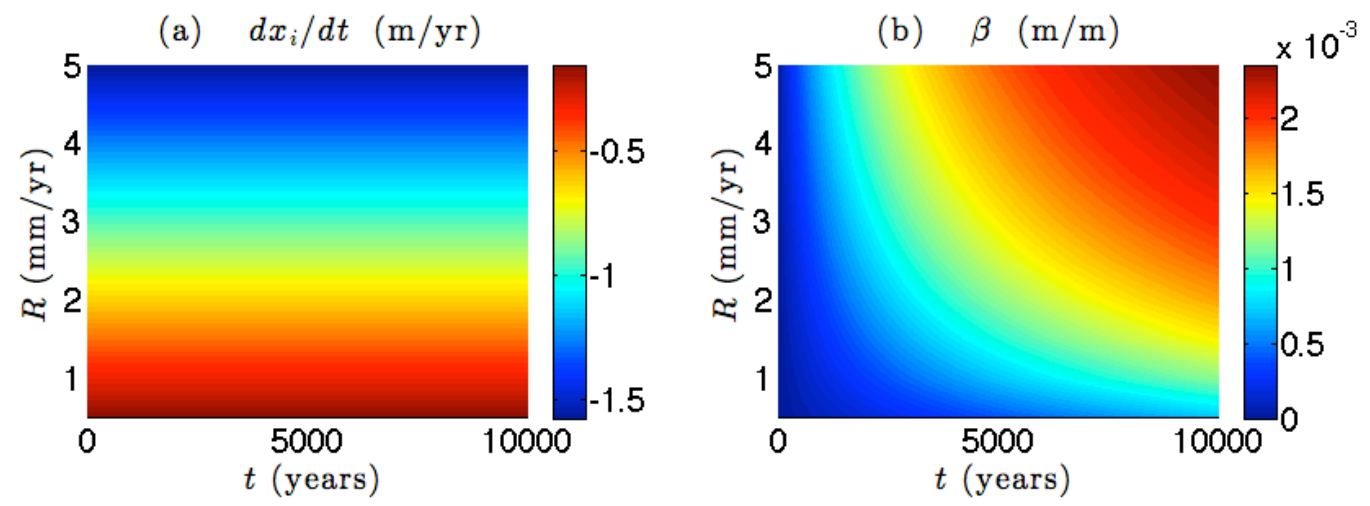

Figure 4: Rate of shoreface retreat $d x_{i} / d t$ (panel a) and bottom slope $\beta$ (panel b) in the $R-t$ space in the case of present-day values of the shelf (Section 2.3.1). 
(a) $t=0$ years

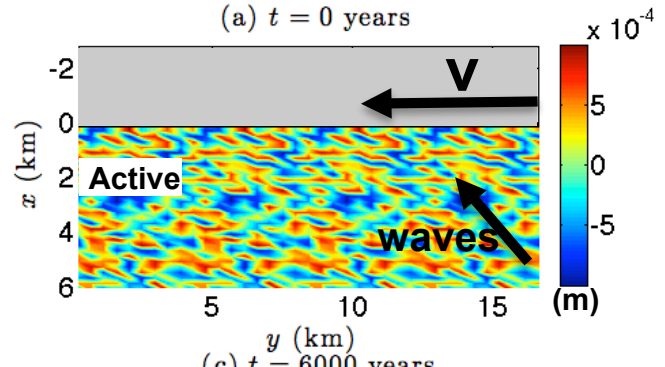

(c) $t=6000$ years

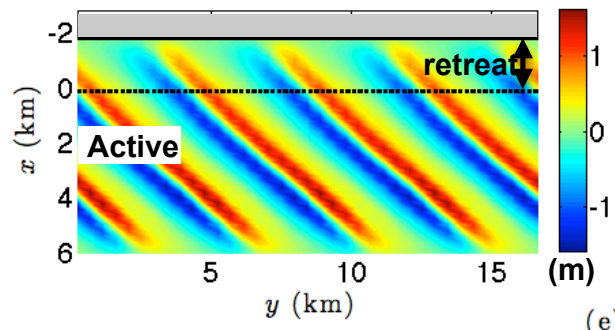

(e) $t=9000$ years

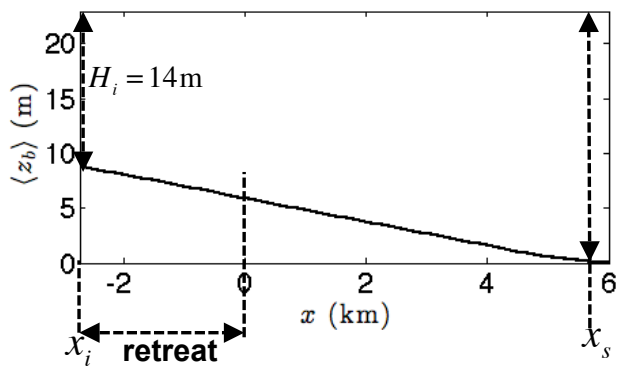

Figure 5: (a-d) Snapshots of the spatial distribution of bottom perturbations $h(x, y, t)(\mathrm{m})$ in the $x$ - $y$ domain for the default case $\left(H_{0}=14 \mathrm{~m}\right.$ and $\left.R=1 \mathrm{~mm} / \mathrm{yr}\right)$ at times $t=0$ years (panel a), $t=3000$ years (panel b), $t=6000$ years (panel c), and $t=9000$ years (panel d). Crests and troughs are indicated by red and blue colors, respectively. Dashed black lines indicate location of the initial transition nearshore zone-inner shelf $\left(x_{i}=0\right)$ and solid black lines denote that of the new transition $\left(x_{i}\right)$. The part of the domain that is not yet part of the inner shelf is indicated by grey. The black arrows in panel (a) indicate directions of storm-driven current and waves. (e) Cross-shore profile of mean bed level $\left\langle z_{b}\right\rangle$ at $t=9000$ years. 
(a)

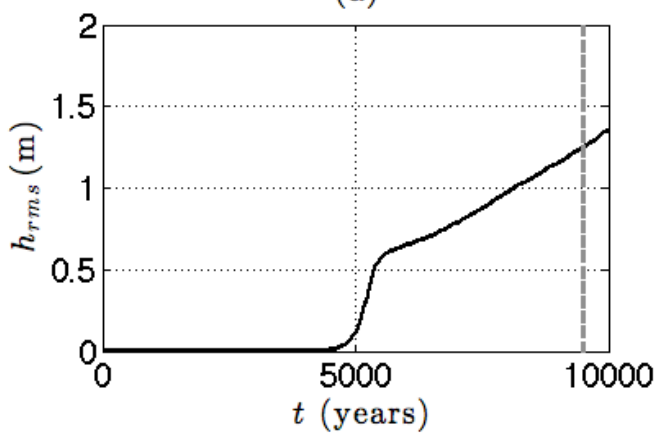

(b)

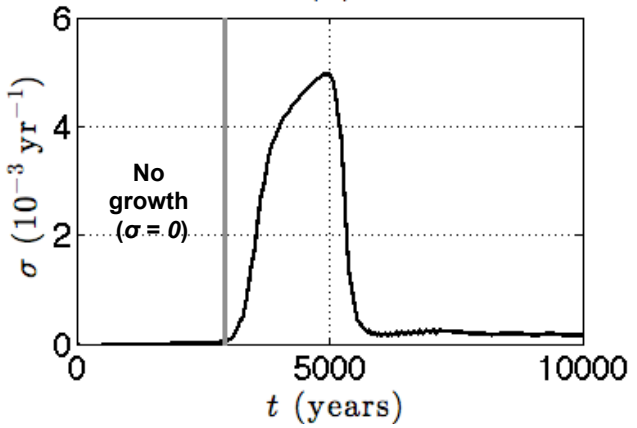

(c)

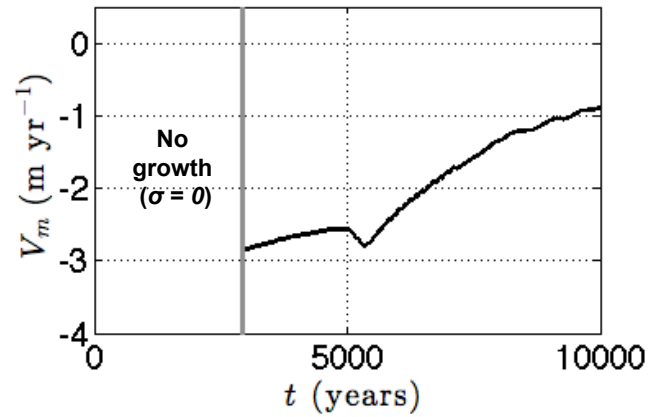

(d)

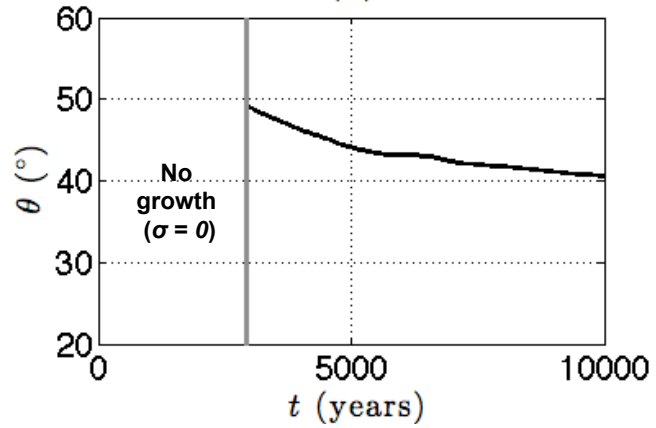

Figure 6: (a) The root-mean-square height $h_{r m s}$ of the sand ridges averaged over the entire inner shelf (i.e. $x_{i} \leq x \leq x_{s}$ ), which remains active during the full simulation time period of 10000 years. (b) As in (a), but for the global growth rate $\sigma$. (c) As in (a), but for the global migration rate $V_{m}$. (d) As in (a), but for the angle of orientation $\theta$ of the ridges with respect to the coast. Variables $V_{m}$ (panel c) and $\theta$ (panel d) are computed from the time $(t \sim 3000$ years, solid grey vertical lines) when bottom perturbations $h$ start to grow $(\sigma>0)$. In panel a, the dashed grey line indicates the time $(\sim 9500$ years $)$ at which the slope $\beta$ has its present-day value $\left(\sim 1.1 \times 10^{-3}\right)$. 
Active

(a) $h_{r m s, A c t i v e}(\mathrm{~m})$

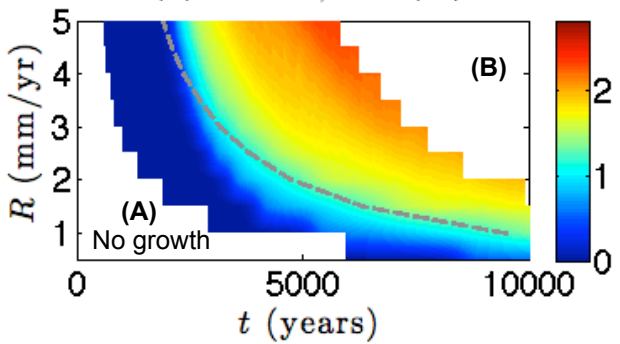

(b) $\sigma_{\text {Active }}\left(10^{-3} \mathrm{yr}^{-1}\right)$

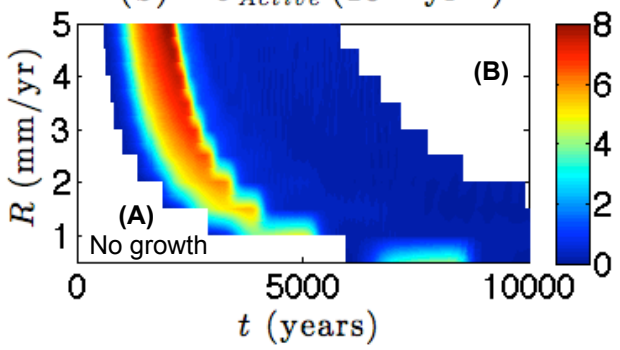

(c) $\left|V_{m, \text { Active }}\right|\left(\mathrm{m} \mathrm{yr}^{-1}\right)$

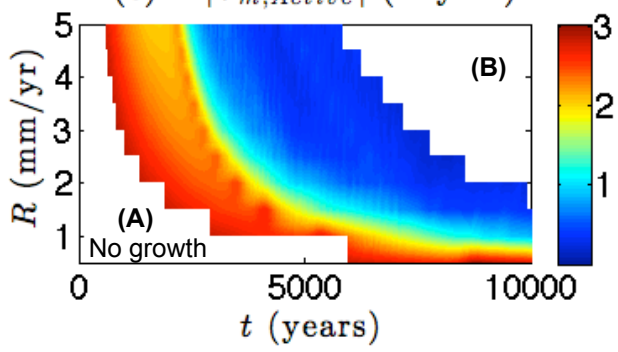

(d) $\theta_{\text {Active }}\left({ }^{\circ}\right)$

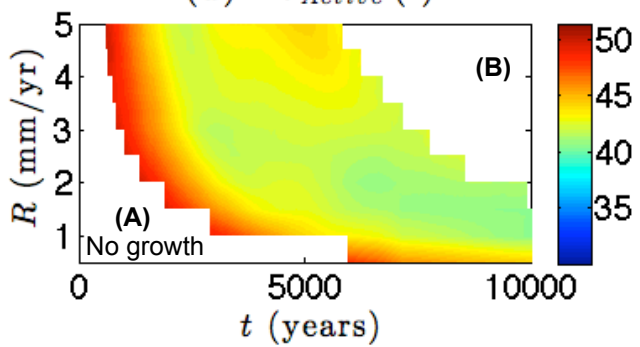

(e) $\overline{h_{\text {rms }, \text { Drowned }}(\mathrm{m})}$
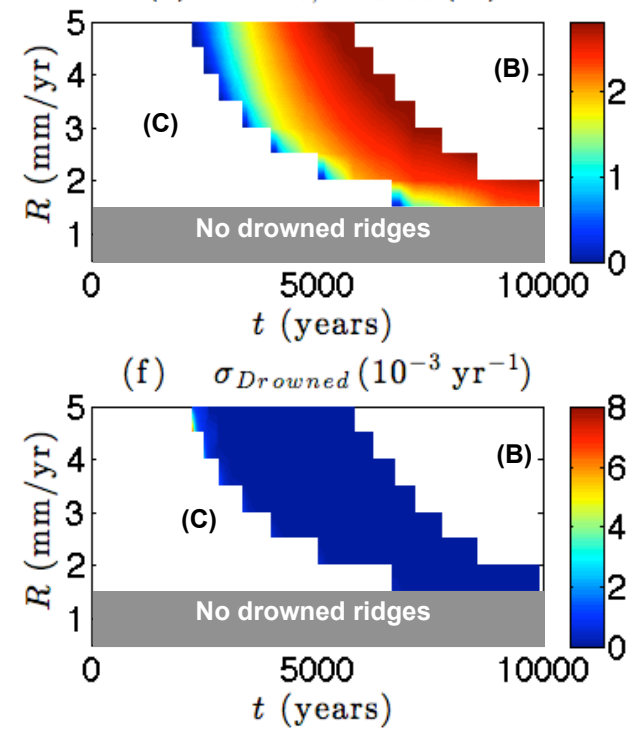

(g) $\left|V_{m, \text { Drowned }}\right|\left(\mathrm{m} \mathrm{yr}^{-1}\right)$

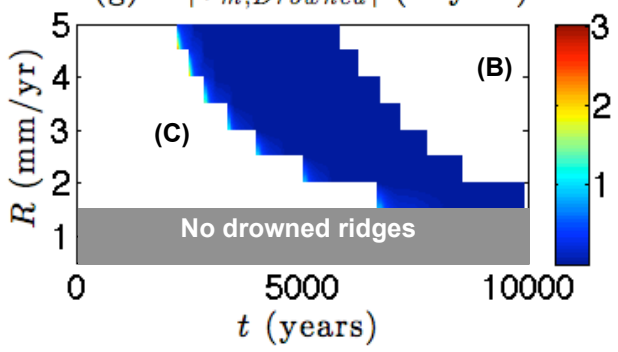

(h) $\theta_{\text {Drowned }}\left({ }^{\circ}\right)$

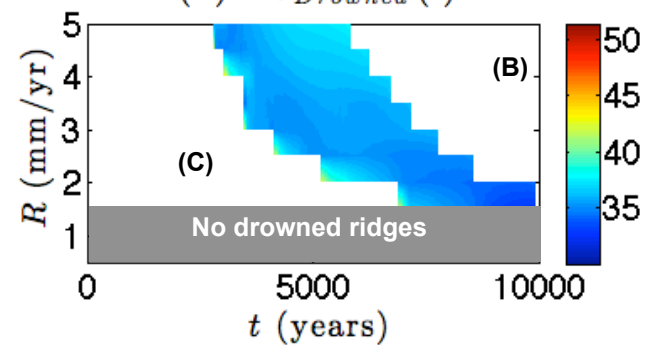

Figure 7: Left (a-d): Contour plots of (a) height $h_{r m s, \text { Active }}$, (b) growth rate $\sigma_{\text {Active }}$, (c) absolute value of migration rate $V_{m, \text { Active }}$ and (d) angle of orientation $\theta_{\text {Active }}$ of the active ridges in the $R-t$ space (experiment 'SensRate1', Table 1). Right (e-h): As in the left panels, but for drowned ridges. The dashed grey line in panel a denotes the times at which the slope $\beta$ has its present-day value $\left(\sim 1.1 \times 10^{-3}\right)$. In area 'A', active ridges have not yet appeared $(\sigma \leq 0)$. In area 'C', drowned ridges are not observed yet $\left(u_{r m s}>u_{c}\right.$, with $\left.u_{c}=0.35 \mathrm{~m} / \mathrm{yr}\right)$, and in the grey area, they do not appear during the entire simulation period. In area 'B', no solutions were obtai4@d with the model. 
(a)

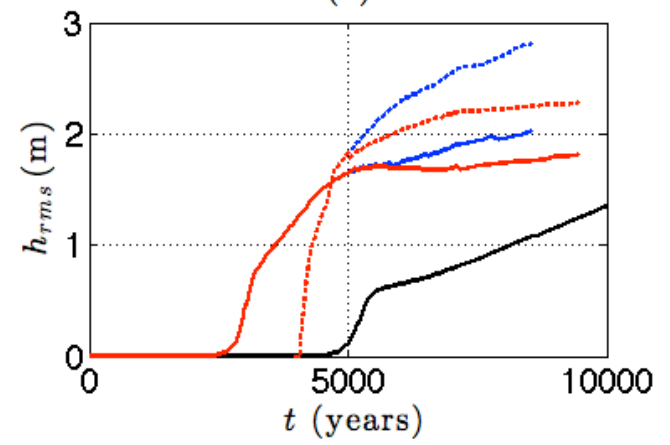

(b)

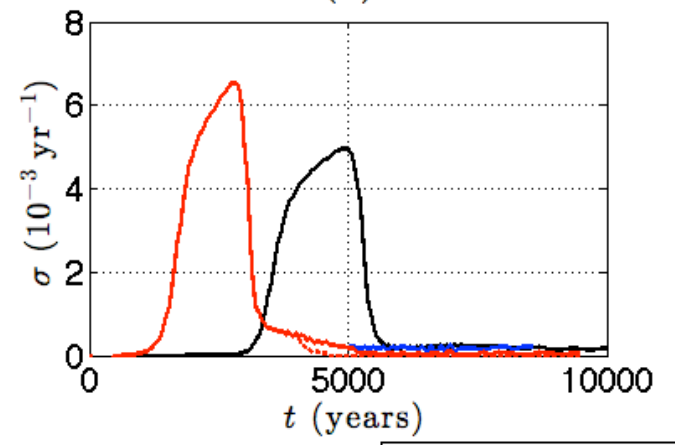

(c)

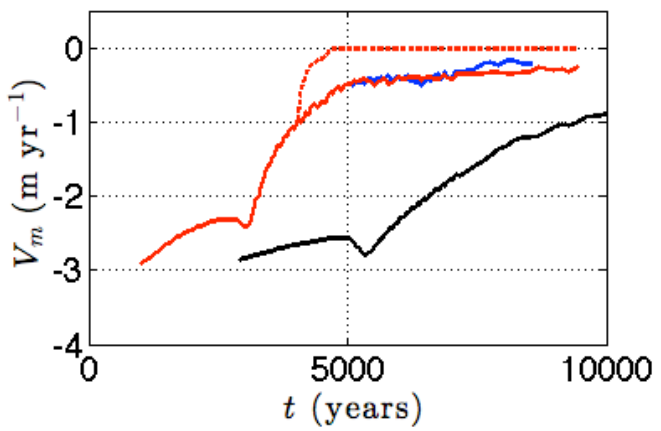

(d)

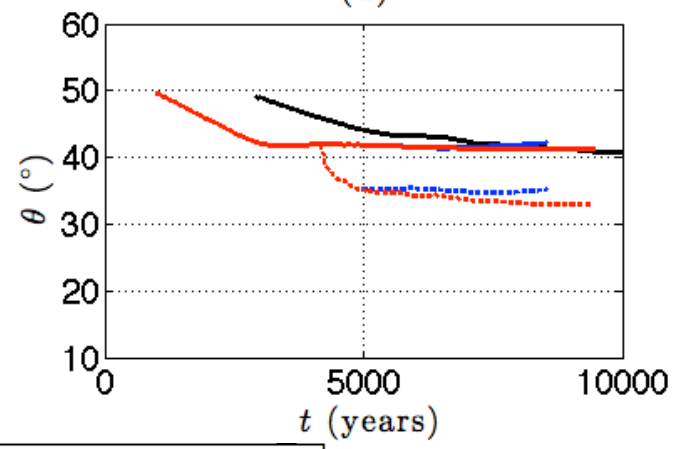



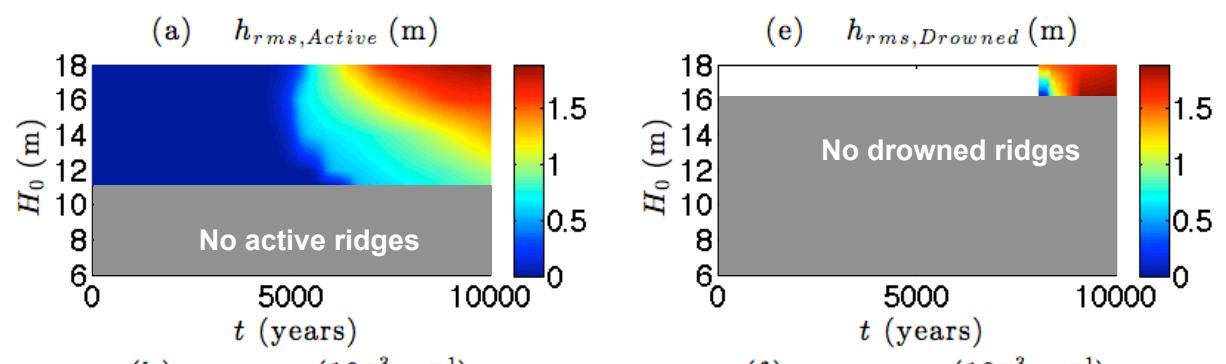

(b) $\sigma_{\text {Active }}\left(10^{-3} \mathrm{yr}^{-1}\right)$

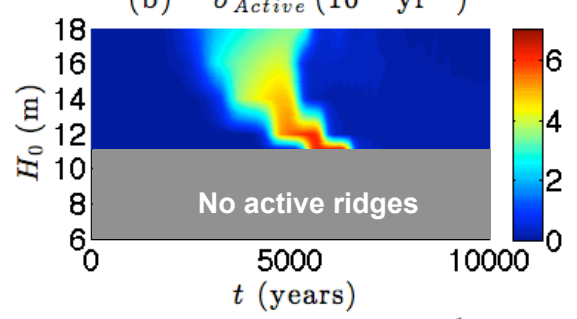

(f) $\sigma_{\text {Drowned }}\left(10^{-3} \mathrm{yr}^{-1}\right)$

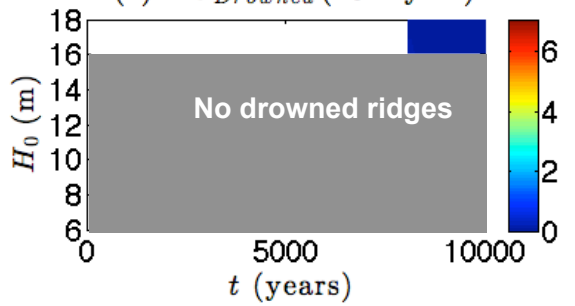

(c) $\mid V_{m, \text { Activd }}\left(\mathrm{m} \mathrm{yr}^{-1}\right)$
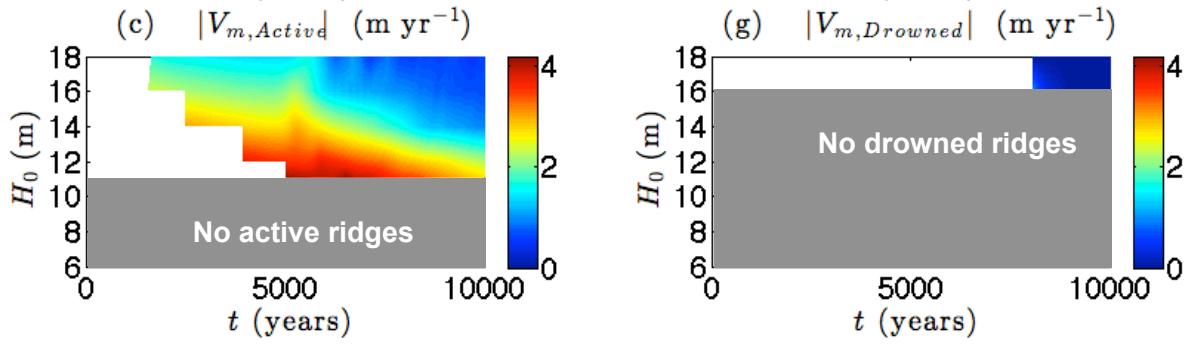

(d) $\theta_{\text {Active }}\left({ }^{\circ}\right)$
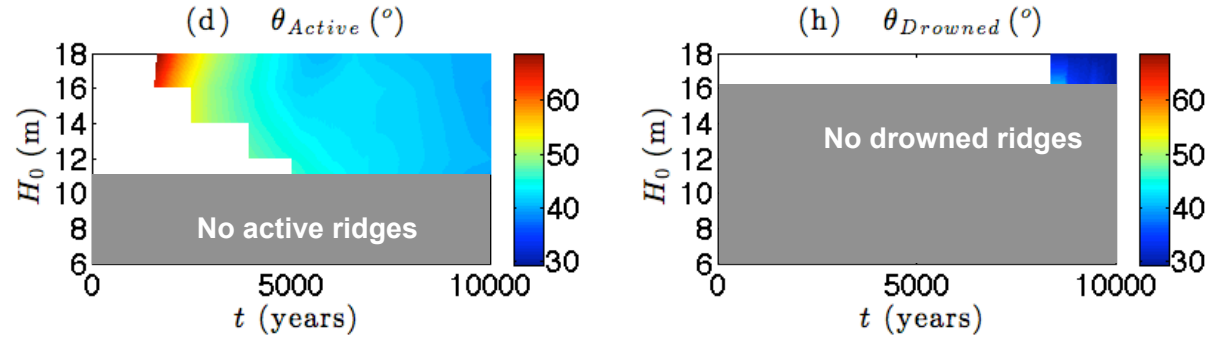

Figure 10: (a-h): As in Fig. 7, but in the $H_{0}-t$ space (experiment 'SensDepth', Table 1). In the grey areas in the left panels, active ridges do not form, and in those in the right panels ridges do not drown. Rate of sea level rise $R=1 \mathrm{~mm} / \mathrm{yr}$. 
(a) $t=7500$ years

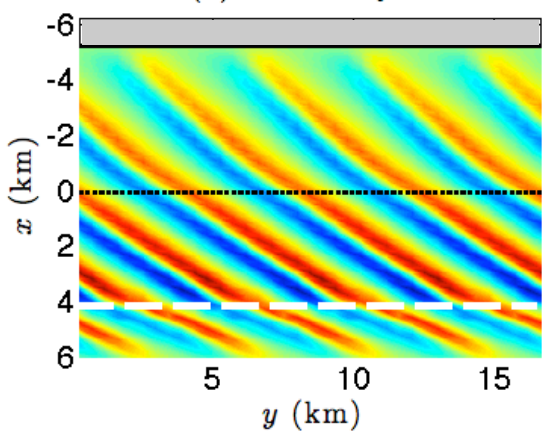

(c) $t=9000$ years

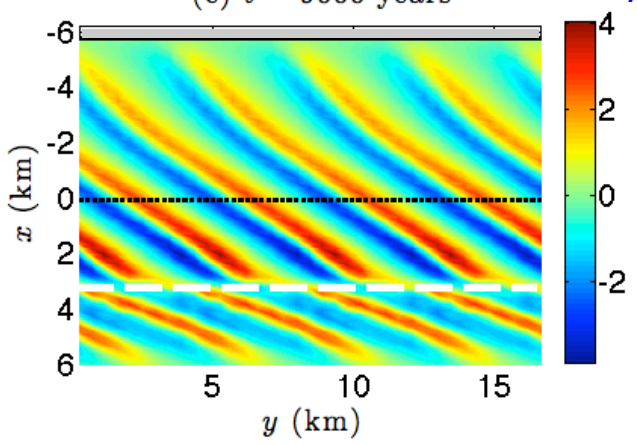

(b) $t=8000$ years
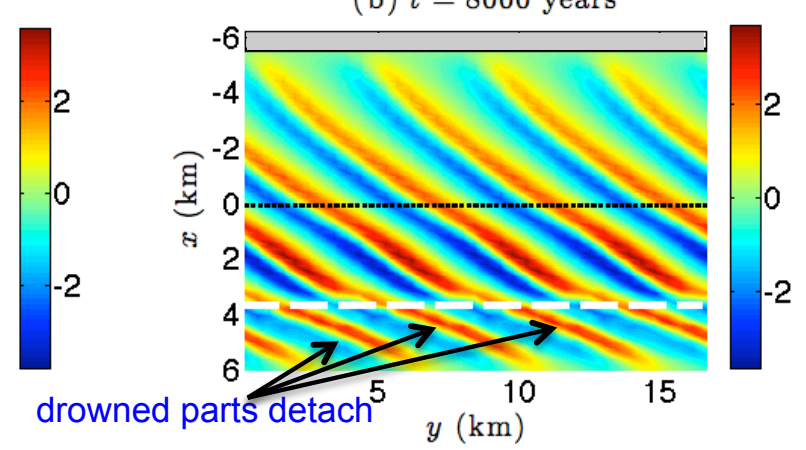

Attached ridges (d) $t=10000$ years

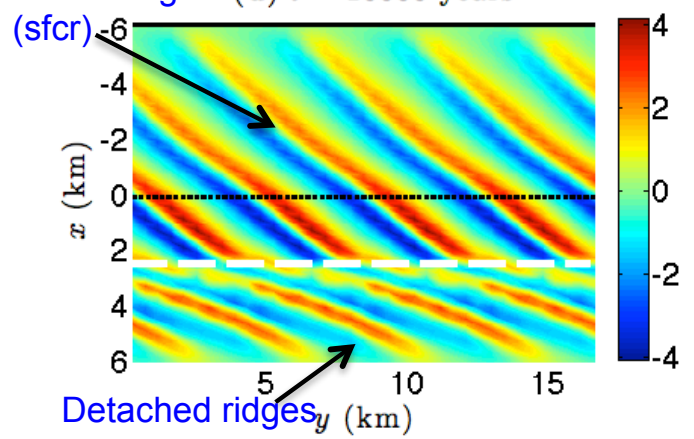

Figure 11: Snapshots of the spatial distribution of bottom perturbations $h$ in the case of a smaller depth and a mixed rate of sea level rise $\left(H_{0}=11 \mathrm{~m}\right.$ and $[2.5 \rightarrow 1] \mathrm{mm} / \mathrm{yr}$; part of experiment 'SensDepth') at times $t=7500$ years (panel a), $t=8000$ years (panel b), $t=9000$ years (panel $\mathrm{c}$ ) and $t=10000$ years (panel $\mathrm{d}$ ). 
(a)

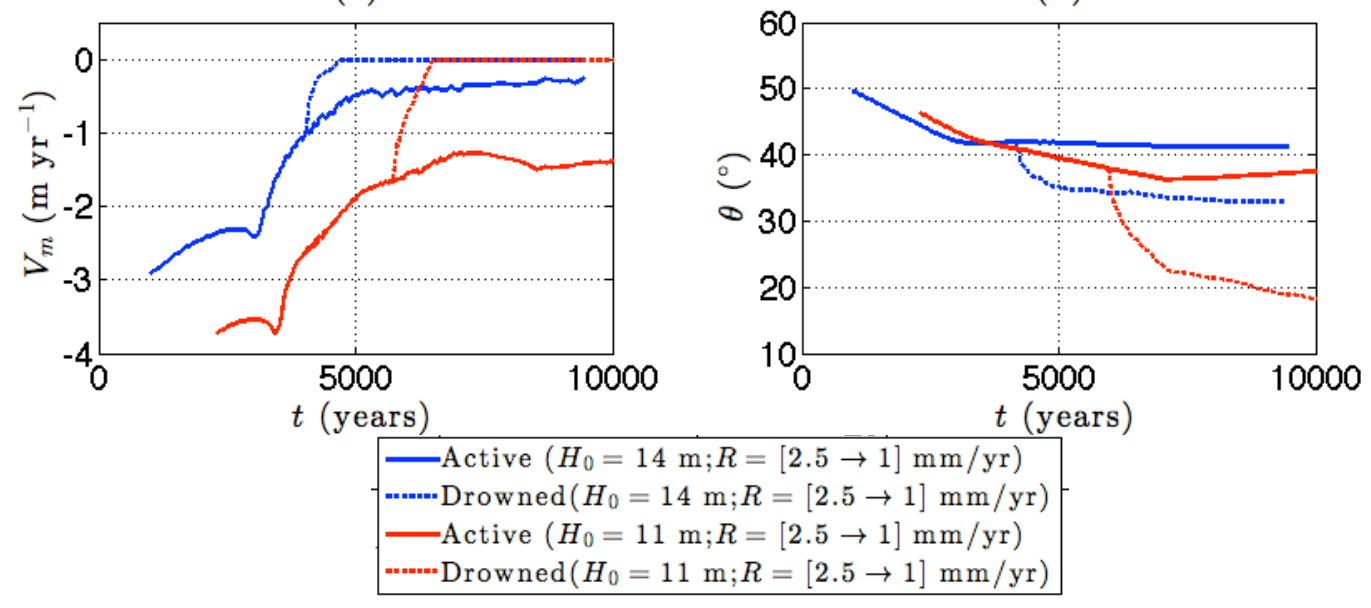

Figure 12: Migration $V_{m}$ (panel a, red lines) and angle $\theta$ (panel b, red lines) in the case that landward depth $H_{0}=11 \mathrm{~m}$ and using a mixed rate of sea level rise $(R=[2.5 \rightarrow 1] \mathrm{mm} / \mathrm{yr})$, versus time. Solid and dashed lines represent active and drowned ridges, respectively. For the sake of comparison, results in the case that $H_{0}=14 \mathrm{~m}$ and $R=[2.5 \rightarrow 1] \mathrm{mm} / \mathrm{yr}$ are plotted as well (blue lines). 

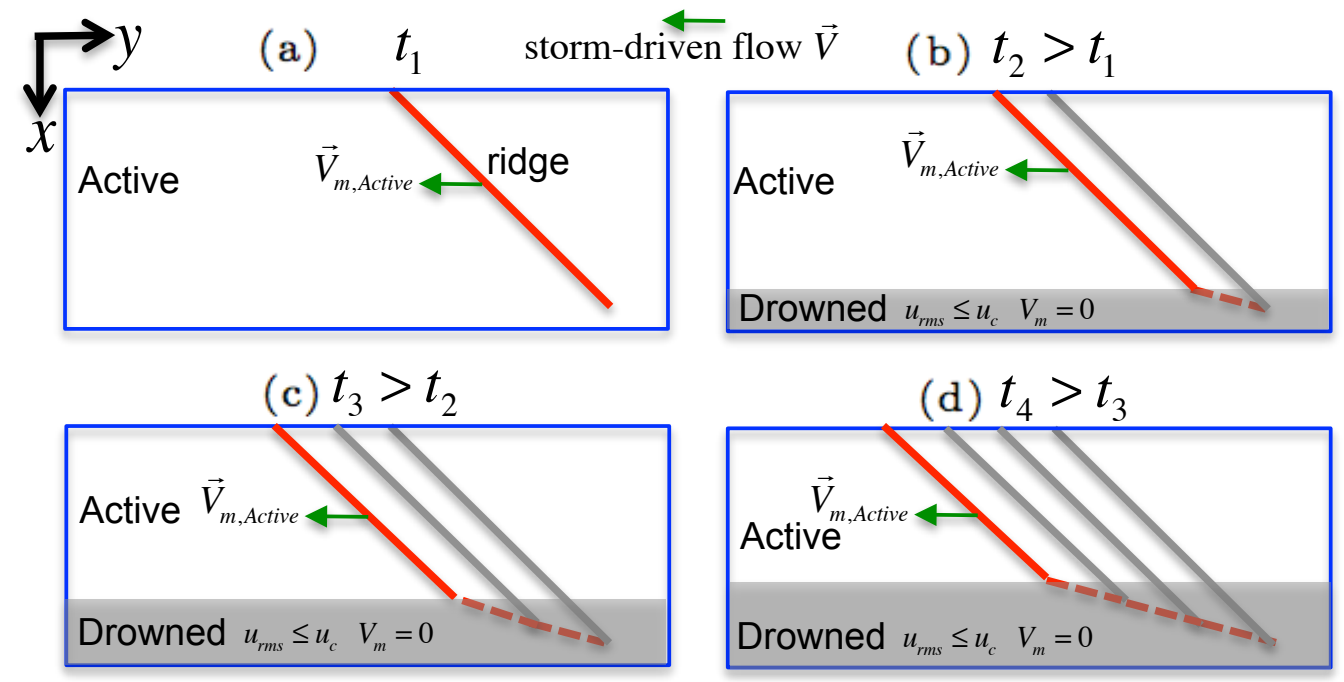

Figure 13: Schematic view illustrating the change in the orientation of the offshore part (dashed red lines) of ridges under a rising sea level and a retreating shoreface (the latter is not plotted for reasons of clarity) at four successive times $t_{1}$ (panel a), $t_{2}$ (panel b), $t_{3}$ (panel c) and $t_{4}$ (panel $\mathrm{d}$ ). Red and grey lines denote positions of the ridge crest at present and at earlier times, respectively. At $t=t_{2}$, in the grey area, wave orbital velocity $u_{r m s}$ is below critical velocity for erosion $u_{c}$, and thus the migration of the offshore part of the ridge in this area vanishes. Meanwhile, the onshore part of the ridge outside this area keeps on migrating. The result is that the offshore part rotates counter-clockwise. At times $t=t_{3}$ and $t=t_{4}$, the rising sea level increases the grey area in the onshore direction, thereby causing the process of differential migration rate between the parts of the ridge inside and outside this area to repeat further up the inner shelf. 


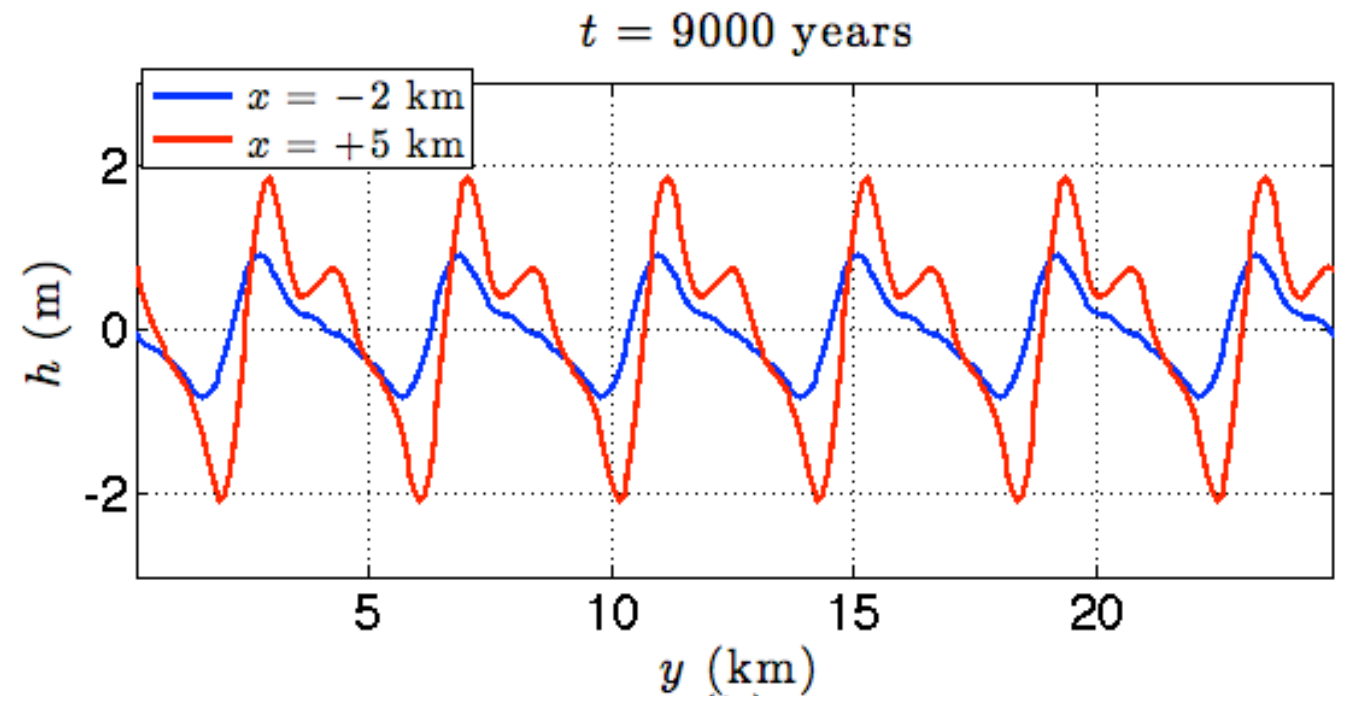

Figure 14: (a) Snapshots of alongshore profiles of $h$ at $x=-2 \mathrm{~km}$ (blue line) and at $x=5 \mathrm{~km}$ (red line) at time $t=9000$ years in the default case. 


\section{${ }_{838 \quad \text { List of Tables }}$}

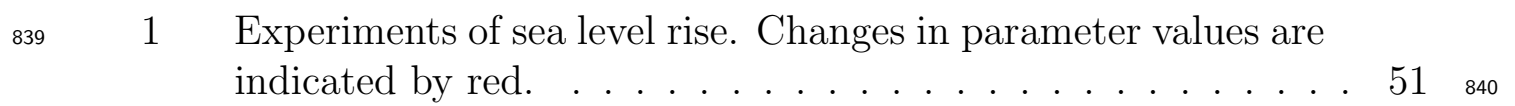


Table 1: Experiments of sea level rise. Changes in parameter values are indicated by red.

\begin{tabular}{|c|l|c|c|c|}
\hline Experiment & $R(\mathrm{~mm} / \mathrm{yr})$ & $H_{0}(\mathrm{~m})$ & $L_{0}(\mathrm{~km})$ & $L_{y}(\mathrm{~km})$ \\
\hline default & 1 & 14 & 5.5 & 4.1 \\
\hline SensRate1 & {$[0.5 ; 1.5 ; 2 ; 2.5 ; 3 ; 3.5 ; 4 ; 4.5 ; 5]$} & 14 & 5.5 & 4.1 \\
\hline SensRate2 & {$[2.5 \rightarrow 1]:$} & 14 & 5.5 & 4.1 \\
& $\begin{array}{l}2.5, \text { for } 0<t<5000 \text { years } \\
1, \text { for } t>5000 \text { years }\end{array}$ & & & \\
\hline SensDepth & {$[1 ; 2.5 ; 5][2.5 \rightarrow 1]$} & $\begin{array}{c}{[6,8,10,11,} \\
12,16,18]\end{array}$ & 5.5 & 4.1 \\
& & 14 & 3 & 4.1 \\
\hline SensWidth & 1 & 14 & 5.5 & {$[3,6,8]$} \\
\hline SensLength & 1 & \multicolumn{2}{|c}{} \\
\hline
\end{tabular}

